\title{
Evaluation of exposures and respiratory health at a coffee processing facility
}

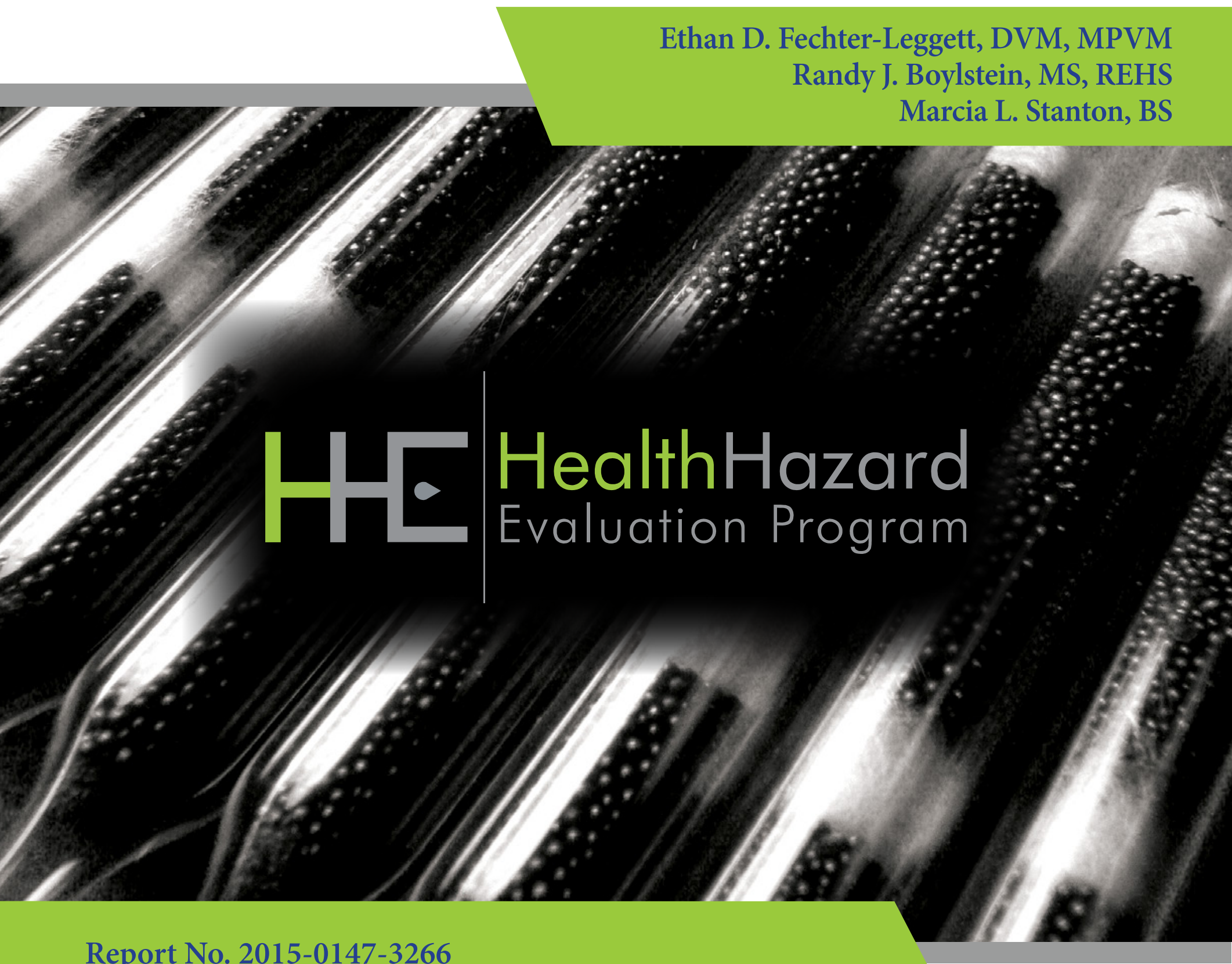

January 2017

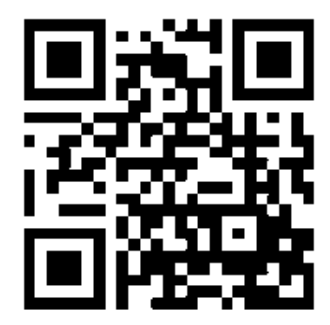

U.S. Department of Health and Human Services Centers for Disease Control and Prevention

National Institute for Occupational Safety and Health

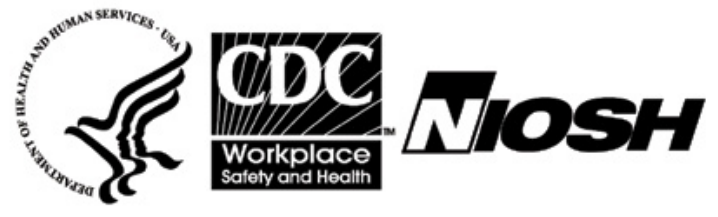




\section{Contents}

Highlights. i

Abbreviations .........................................v

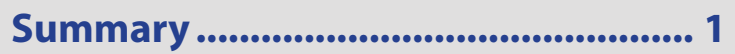

Introduction ......................................... 2

Background............................................. 2

Process Description ................................ 3

Methods .............................................. 4

Results ........................................... 11

Discussion ......................................... 22

Conclusions ...................................... 29

Recommendations............................ 29

Appendix A: Tables .............................. 34

References .......................................... 39

Acknowledgements............................. 46

The employer is required to post a copy of this report for 30 days at or near the workplace(s) of affected employees. The employer must take steps to ensure that the posted report is not altered, defaced, or covered by other material.

The cover photo is a close-up image of sorbent tubes, which are used by the HHE Program to measure airborne exposures. This photo is an artistic representation that may not be related to this Health Hazard Evaluation. 


\section{Highlights of this Evaluation}

The Health Hazard Evaluation Program received a request from management of a coffee processing facility. The management was concerned about exposures to and health effects from diacetyl during coffee roasting, grinding, and flavoring.

\section{What We Did}

- We visited the coffee processing facility in February 2016.

- We collected full-shift (hours), task (minutes), and instantaneous (seconds) air samples to measure air levels of the alpha-diketones diacetyl, 2,3-pentanedione, and 2,3-hexanedione.

- We collected roasted coffee beans and liquid flavorings to measure their emission potential for diacetyl, 2,3-pentanedione, and 2,3-hexanedione.

- We performed continuous air sampling for volatile organic compounds, carbon monoxide, and carbon dioxide in the roasting, packaging, and grinding/ flavoring areas.

- We assessed the facility's ventilation system.

- We observed for dampness, mold, and signs of water damage.

- We interviewed and tested the lung function of four employees.

\section{What We Found}

- All full-shift personal air samples collected using the standard method (with tubes) were below the National Institute for Occupational Safety and Health's recommended exposure limits for diacetyl (5 parts per billion) and 2,3-pentanedione (9.3 parts per billion).

We evaluated respiratory health and potential exposures to the alphadiketones diacetyl, 2,3-pentanedione, and 2,3-hexanedione, other volatile organic compounds, carbon monoxide, and carbon dioxide among employees at a coffee processing facility that produced unflavored and flavored coffee. Fullshift average air levels of diacetyl and 2,3-pentanedione in the facility were not elevated. However, the short-term average air levels from our air sampling during shortterm tasks identified several tasks with higher exposures to diacetyl and 2,3-pentanedione than other tasks. Although the health effects of these short-term exposures are currently not known, we recommend a precautionary approach to limit employees' exposures using engineering and administrative controls. Because the facility uses flavorings containing diacetyl and 2,3-pentanedione, we also recommend a medical monitoring program.

- All full-shift area air samples collected using the standard method (with tubes) were 
below the recommended exposure limits for diacetyl and 2,3-pentanedione, except for one diacetyl sample obtained outside the facility.

- Full-shift area air samples collected using a canister method were above the recommended exposure limit for diacetyl in the showroom, the warehouse, and near the roasting area.

- Air levels of diacetyl and/or 2,3-pentanedione were higher for tasks involving packaging, flavoring, and grinding flavored coffee beans than roasting coffee beans.

- All tested coffee beans and liquid flavorings had potential to emit diacetyl and 2,3-pentanedione.

- Carbon monoxide levels were above the National Institute for Occupational Safety and Health's ceiling limit of 200 parts per million at open storage bins of roasted coffee beans.

- There were opportunities for air from the production room to enter the office areas.

- The roaster exhaust stack was partially plugged with chaff and debris.

- There was water staining on a ceiling tile in the restroom and a damp wooden beam above the ceiling tiles in an office.

- There were mouse droppings above the ceiling tiles in an office.

- Some employees reported respiratory symptoms. All spirometry tests were normal.

\section{What the Employer Can Do}

- Work with the building owner or a ventilation engineer to modify the existing ventilation system to separate the showroom/reception, kitchen, and office areas from the production room and warehouse areas.

- The National Institute for Occupational Safety and Health's recommended short-term exposure limits for diacetyl and 2,3-pentanedione are for 15-minute samples. For taskbased sampling times of less than 15 minutes, we do not know if exposures to diacetyl and 2,3-pentanedione at the levels we measured are harmful. As a precaution, consider taking steps to reduce employees' exposures during higher exposure tasks (flavoring, grinding, and packaging) by:

○ Limiting access to the area while higher exposure tasks are occurring;

- Relocating higher exposure tasks to a more naturally well-ventilated area, such as next to an open warehouse bay door;

- Weather permitting, opening the warehouse bay door and using accessory fans;

○ Installing local exhaust ventilation around higher exposure tasks.

- Continue to cover bins of roasted beans to reduce emissions of alpha-diketones, carbon monoxide, and carbon dioxide into the air.

- Encourage employees to avoid placing their heads near or inside roasted bean bins. 
- To prevent air from moving from the production areas into the office areas:

$\circ$ Keep the window between the production room and the shared office closed at all times.

- Close the louvered vent above the door that separates the production room and the kitchen and office areas.

- Regularly empty the espresso machine discharge container located under the cabinet in the showroom.

- Follow manufacturer's guidelines for routine maintenance of the rooftop and mobile evaporative coolers to keep water fresh and to prevent scale and mineral deposit formation.

- Follow manufacturer's guidelines for periodic cleaning of the roaster's exhaust.

- Identify the source of the moisture problem and repair to avoid future water incursion.

- Remove and replace any moisture-damaged materials.

- Assess current pest control procedures and develop or evaluate a pest control program as needed to remove potential exposure to animals or animal products (e.g., dander, hair, fur, saliva, and body wastes) that contain allergens that can cause respiratory and skin disorders.

- Encourage employees to report new or ongoing respiratory symptoms to their personal healthcare providers and to a designated individual at the workplace.

- Institute a medical monitoring program for all employees who work in or enter areas where coffee is flavored. Employees who work in or enter these areas for 40 or more hours per year should be included in the medical monitoring program.

\section{What Employees Can Do}

- Whenever possible, avoid spending time in the immediate area during flavoring, grinding, and packaging.

- Weather permitting and as instructed by your employer, open the warehouse bay door and use accessory fans during flavoring, grinding, and packaging of roasted coffee beans.

- Use any local exhaust ventilation as instructed by your employer when it is installed.

- Avoid placing your head near or inside roasted coffee bean bins.

- Report signs of water incursions or pests to your employer.

- Report new or ongoing respiratory symptoms to your personal healthcare provider and a designated individual at your workplace.

- Participate in your employer's medical monitoring program as instructed by your employer. 
This page left intentionally blank 


\section{Abbreviations}

$\begin{array}{ll}{ }^{\circ} \mathrm{F} & \text { degrees Fahrenheit } \\ \text { ACGIH } & \text { American Conference of Governmental Industrial Hygienists } \\ \text { AL } & \text { Action level } \\ \text { ANSI } & \text { American National Standards Institute } \\ \text { cfm } & \text { Cubic feet per minute } \\ \text { CFR } & \text { Code of Federal Regulations } \\ \text { CO } & \text { Carbon monoxide } \\ \text { CO } & \text { Carbon dioxide } \\ \text { FVC } & \text { Forced vital capacity } \\ \text { FEV1 } & \text { 1-second forced expiratory volume } \\ \text { HEPA } & \text { High efficiency particulate air } \\ \text { Hz } & \text { Hertz } \\ \text { IDLH } & \text { Immediately dangerous to life or health } \\ \text { IOS } & \text { Impulse oscillometry } \\ \text { LOD } & \text { Limit of detection } \\ \text { mL } & \text { Milliliter } \\ \text { mL/min } & \text { Milliliter per minute } \\ \text { NHANES } & \text { National Health and Nutrition Examination Survey } \\ \text { NIOSH } & \text { National Institute for Occupational Safety and Health } \\ \text { OSHA } & \text { Occupational Safety and Health Administration } \\ \text { PEL } & \text { Permissible exposure limit } \\ \text { ppb } & \text { Parts per billion } \\ \text { ppm } & \text { Parts per million } \\ \text { REL } & \text { Recommended exposure limit } \\ \text { STEL } & \text { Thort-term exposure limit } \\ \text { TLV } & \text { TWA }\end{array}$




\section{Summary}

In August 2015, the National Institute for Occupational Safety and Health (NIOSH) received a management request for a health hazard evaluation at a coffee processing facility. The request expressed concern about exposure to diacetyl (2,3-butanedione) during coffee roasting, grinding, and flavoring.

In February 2016, we conducted a ventilation assessment, an industrial hygiene survey, and a medical survey. The industrial hygiene survey consisted of the collection of air samples and bulk samples of coffee and flavorings for the analysis of diacetyl, 2,3-pentanedione, and 2,3-hexanedione. Continuous monitoring instruments were used to monitor total volatile organic compounds, carbon monoxide, carbon dioxide, temperature, and relative humidity in specific areas and during tasks. The medical survey consisted of breathing tests and a questionnaire covering medical and work histories.

Overall, average air levels of diacetyl, 2,3-pentanedione, and 2,3-hexanedione were not elevated. We identified specific work tasks that resulted in higher air concentrations of diacetyl and 2,3-pentanedione than other tasks. Specifically, packaging and flavoring tasks were associated with the highest levels of diacetyl and 2,3-pentanedione. Some employees reported respiratory symptoms or diagnoses and/or had abnormal lung function tests. We recommend using engineering and administrative controls as a precautionary approach to limit employees' exposures and establishing a medical monitoring program. 


\section{Introduction}

In August 2015, the Health Hazard Evaluation Program of the National Institute for Occupational Safety and Health (NIOSH) received a request from management of a coffee processing company. The requestor had concerns about health issues related to exposure to diacetyl during the coffee roasting, grinding, and flavoring processes. The health concern was potential lung damage. In February 2016, we visited the facility to learn more about coffee processing and to conduct industrial hygiene and medical surveys. We provided a letter detailing our evaluation and preliminary recommendations to management in February 2016.

\section{Background}

Diacetyl (2,3-butanedione) and 2,3-pentanedione (acetyl propionyl) are kinds of volatile organic compounds (VOCs) known as alpha-diketones that are added as ingredients in food flavorings used in some food products such as microwave popcorn, bakery mixes, and flavored coffee [Day et al. 2011; Kanwal et al. 2006; Bailey et al. 2015]. Diacetyl, 2,3-pentanedione, other VOCs, and gases such as carbon monoxide (CO) and carbon dioxide $\left(\mathrm{CO}_{2}\right)$ are naturally produced and released during the coffee roasting process [Duling et al. 2016; Raffel and Thompson 2013; Daglia et al. 2007; Nishimura et al. 2003; Newton 2002]. Grinding roasted coffee beans produces a greater surface area for off-gassing (sometimes called degassing) of these compounds [Akiyama et al. 2003]. Often coffee roasting facilities package newly roasted coffee in permeable bags or in bags fitted with a one-way valve to allow the coffee to off-gas after it is packaged. Sometimes, newly roasted coffee is placed in bins or containers and allowed to off-gas before packaging. NIOSH has recommended exposure limits (RELs) for diacetyl and 2,3-pentanedione in workplace air [NIOSH 2016]. The NIOSH objective in establishing RELs for diacetyl and 2,3-pentanedione is to reduce the risk of respiratory impairment (decreased lung function) and the severe irreversible lung disease obliterative bronchiolitis associated with occupational exposure to these chemicals.

2,3-Hexanedione is also an alpha-diketone that is sometimes used as a substitute for diacetyl and is produced naturally during coffee roasting. In a study using animals, there was some evidence that 2,3-hexanedione might also damage the lungs, but it appeared to be less toxic than diacetyl and 2,3-pentanedione [Morgan et al. 2016]. There are no established occupational exposure limits for 2,3-hexanedione.

Employees at another coffee processing facility that used flavorings developed obliterative bronchiolitis [CDC 2013]. A NIOSH health hazard evaluation at that facility demonstrated elevated levels of diacetyl and 2,3-pentanedione throughout the facility and exposure-related adverse respiratory health effects in the current workforce [Duling et al. 2016; Bailey et al. 2015]. Based on these findings, the coffee processing company that is the subject of this report wanted to be proactive, and thus management submitted a health hazard evaluation request to NIOSH to characterize potential exposures and perform a ventilation assessment; the management also agreed to a health evaluation. 


\section{Process Description}

The coffee processing facility had four employees (including the owner) and was located in a multi-unit structure in an industrial setting. The facility roasted, ground, flavored, and packaged coffee for wholesale distribution primarily to coffee shops and cafes. The coffee processing facility received green coffee beans in burlap bags from around the world including, but not limited to, Colombia, Guatemala, Mexico, and Brazil. Upon arrival at the facility, the bags of green beans were stored on pallets in the warehouse. Once a bag was opened, it was stored on the floor next to the roaster. To prepare a batch for roasting, a roaster operator scooped a desired amount of coffee beans from a bag of green coffee beans into a 5-gallon plastic bucket. The contents of the bucket were then dumped into the hopper at the top of the roaster. When ready, the operator pulled a lever allowing the beans to enter the roaster. The beans were heated to a specific temperature and for a specific time period for the desired roast. Time and temperature varied between different types of roasts. At the end of each cycle, the roaster operator pulled a lever which allowed the roasted beans to drop into a cooling bin where they were agitated by a rotating arm. The cooling bin utilized a downdraft exhaust system that drew air over the roasted beans to accelerate cooling. The downdraft system exhausted through the roaster and then to an exhaust stack on the roof through a ventilation pipe. The roaster operator monitored the roasting equipment throughout the roasting and cooling process. After cooling, the roasted beans were dispensed from the cooling bin into approximately 30 -gallon plastic containers with lids. The roaster operator then manually moved the plastic containers to a storage area, approximately 10 feet from the roaster, until needed for further processing, including grinding and packaging. The roaster operator periodically brewed roasted coffee for quality control purposes.

In the packaging area, orders for whole bean coffee were filled by scooping roasted beans from the desired storage containers into bags placed on a scale. Bags consisted of one, two, and five pound paper and two and five pound plastic fitted with exhaust valves, or fractional foil bags used for ground coffee. For ground coffee, an employee took pre-weighed bags of roasted whole beans to the grinding area, manually emptied the coffee beans into a grinder, and then placed the packages at the bottom of the grinder to collect the ground coffee. There were two grinding machines, one for flavored coffee beans and one for unflavored coffee beans. The grinders could be adjusted for type of grind (e.g., coarse, medium, or fine). After processing, bags of coffee were stored in open cardboard boxes while awaiting pickup or delivery.

When orders were requested for flavored coffee, an employee took pre-weighed bags of roasted whole beans to the flavoring area near the grinding area, and roasted beans were poured into a 5-gallon plastic bucket with a lid. Liquid flavorings, kept in plastic bottles, were dispensed with a small scoop into the bucket of coffee beans. Once the lid on the plastic bucket was secured, an employee manually agitated the bucket for less than 1 minute. When completed, the employee poured the coffee back into the pre-weighed bag, and the process was repeated until the order was complete. If necessary, whole bean flavored coffee was ground in the grinder dedicated for flavored coffee and then repackaged. More than 10 different flavorings were used; commonly used flavorings were amaretto, French vanilla, and hazelnut. 
Each morning, before starting operations, the roaster operator used a portable vacuum to clean the roaster and remove accumulated chaff under the cooling bin from the previous day's operations. The vacuum did not contain a high efficiency particulate air (HEPA) filter. Employees wore street clothes rather than a uniform or any personal protective equipment. A showroom, kitchen area, and two administrative offices (the owner's office and a shared office) were located in the front of the facility.

\section{Methods}

We visited the coffee processing facility in February 2016. We held an opening meeting with management and an employee representative; performed a ventilation assessment; collected air samples; conducted confidential medical interviews; and administered breathing tests. At the conclusion of our site visit we held a closing meeting with management and an employee representative. We provided a letter detailing our evaluation and preliminary recommendations to management in February 2016.

The objectives for the evaluation were the following:

1. Measure employees' exposure to VOCs with a focus on diacetyl and 2,3-pentanedione during coffee processing;

2. Identify process areas or work tasks that were associated with elevated levels of diacetyl and 2,3-pentanedione;

3. Measure levels of $\mathrm{CO}$ and $\mathrm{CO}_{2}$ in areas of the facility;

4. Assess ventilation systems and their effect on exposure levels;

5. Determine if any employees had respiratory symptoms or abnormal lung function tests; and

6. Measure the amount of nitric oxide in employees' exhaled breath.

\section{Ventilation Assessment}

On February 1, 2016, we took physical measurements of all rooms and calculated approximate room volumes. Air flow measurements of supply vents and exhaust outlets were taken using a TSI Accubalance Plus Model 8373 Air Capture Hood (TSI Incorporated, St. Paul, MN). The complete set of ventilation measurements allowed the calculation of volumetric flow rates in cubic feet per minute $(\mathrm{cfm})$ into and out of each area. A Wizard Stick Handheld Fog Generator (Educational Innovations, Inc., Bethel, CT) was used to visualize air movement as an indication of pressure differentials between various areas of the facility to investigate whether contaminants were effectively captured and removed by the ventilation system. Temperature, humidity, $\mathrm{CO}$, and $\mathrm{CO}_{2}$ measurements were obtained during room dimension and air flow measurements. 


\section{Industrial Hygiene Survey}

Sampling Times for Alpha-Diketones

For diacetyl, 2,3-pentanedione, and 2,3-hexanedione, the air samples were collected over hours, minutes, and seconds as described below. Samples collected over hours can help determine average concentrations that can be compared to the NIOSH RELs for diacetyl and 2,3-pentanedione. These average concentrations might not tell us about short-term peak exposures that could be relevant to respiratory health, particularly when tasks are repeated multiple times per day. Therefore, during particular tasks, we collected air samples over several minutes. These task samples were often shorter or longer than 15 minutes so they cannot be directly compared to 15-minute short-term exposure limits (STELs) but can provide information about which tasks have relatively higher exposures. To help identify point sources of chemicals, we also performed real-time sampling and collected instantaneous samples that were collected over several seconds.

\section{Air Sampling and Analysis Using OSHA Methods 1013/1016}

During three days of air sampling, February 2-4, 2016, we collected personal and area air samples for diacetyl, 2,3-pentanedione, and 2,3-hexanedione on silica gel sorbent tubes throughout the facility. The samples were collected and analyzed according to the OSHA sampling and analytical Method 1013 [OSHA 2008] for diacetyl, Method 1016 [OSHA 2010] for 2,3-pentanedione, and a modified OSHA 1013/1016 method for 2,3-hexanedione [LeBouf et al. 2012]. In accordance with these methods, two glass silica gel sorbent tubes were connected by a piece of tubing and inserted into a protective, light-blocking cover. The tubes were connected in series to a sampling pump pulling air through the tubes at a flow rate of 50 milliliters per minute $(\mathrm{mL} / \mathrm{min})$. The sampling setup was attached to an employee's breathing zone or in an area basket at various places throughout the facility. For full-shift sampling, we collected two consecutive 3-hour samples and calculated the time-weight average (TWA) concentration from the two samples, assuming that the total 6-hour monitoring results reflected a full work shift (8-hour) TWA exposure. We refer to these samples as "full-shift samples" throughout this report. We also collected short-term task samples in the same manner, but the sampling pump flow rate was $200 \mathrm{~mL} / \mathrm{min}$ as detailed in OSHA Methods 1013/1016 [OSHA 2008; 2010]. Analyses of the samples were performed at the NIOSH Respiratory Health Division's Organics Laboratory. Briefly, the samples were extracted for 1 hour in 95\% ethanol:5\% water containing 3-pentanone as an internal standard. Samples were analyzed using an Agilent 7890/7001 gas chromatograph/mass spectrometer system operated in selected ion monitoring mode for increased sensitivity compared to the traditional flame ionization detector used in OSHA Methods 1013/1016 [LeBouf and Simmons 2016].

The limits of detection (LOD) were 0.02 micrograms per sample ( $\mu \mathrm{g} / \mathrm{sample}$ ) for diacetyl, 2,3-pentanedione, and 2,3-hexanedione. These LODs equate to 0.6 parts per billion (ppb) for diacetyl, $0.5 \mathrm{ppb}$ for 2,3-pentanedione, and $0.5 \mathrm{ppb}$ for 2,3-hexanedione for a typical fullshift TWA air sample but will vary depending on the volume of sample collected. The LODs in ppb for task samples are generally higher than typical LOD values for full-shift samples because the air volumes collected during task sampling are lower. When the values presented in the report are from samples below the LOD they are denoted by a "<" symbol. The limits of quantitation equate to $2.0 \mathrm{ppb}$ for diacetyl, $1.7 \mathrm{ppb}$ for 2,3-pentanedione, and $1.7 \mathrm{ppb}$ for 
2,3-hexanedione for a typical full-shift TWA air sample.

\section{Air Sampling and Analysis Using Evacuated Canisters}

We collected area TWA and instantaneous air samples for airborne alpha-diketones in evacuated canisters during the three days of air sampling. The canister sampling setup consisted of a 450 milliliter (mL) evacuated canister equipped with either an instantaneous or restricted flow controller; these flow controllers were set for a 6-hour TWA duration or an instantaneous duration ( $<30$ seconds). The 6-hour sampling setup was attached via a Teflon sampling tube to an area sampling basket alongside the glass silica gel tube sampling train. Instantaneous samples were taken by opening the evacuated canister to grab a sample of air to help identify point sources of alpha-diketones. We also used two 6-liter canisters to collect two overnight air samples on the night of February 2, 2016.

The canister air samples were analyzed using a pre-concentrator/gas chromatograph/mass spectrometer system pursuant to a published method validation study [LeBouf et al. 2012], which included the following analytes: ethanol, acetone, methylene chloride, hexane, chloroform, benzene, methyl methacrylate, toluene, ethylbenzene, m,p-xylene, o-xylene, alpha-pinene, and limonene. The method was modified as follows: the pre-concentrator was a Model 7200 (Entech Instruments, Inc.), and six additional analytes were included (acetaldehyde, acetonitrile, styrene, diacetyl, 2,3-pentanedione, and 2,3-hexanedione). At present, this canister method is partially validated [Lebouf et al. 2012] and not considered the standard method. The LOD for diacetyl was $0.78 \mathrm{ppb}$, for 2,3-pentanedione was $1.08 \mathrm{ppb}$, and for 2,3-hexanedione was $1.92 \mathrm{ppb}$, based on a three-times dilution factor, which is typical for restricted flow controller samples. However, LODs are dependent on canister pressure and might be higher or lower than typical LOD values.

\section{Bulk Sampling and Headspace Analysis}

We used 50-mL sterile polypropylene centrifuge tube containers to collect approximately 40-mL bulk samples of five roasted coffees (whole bean or ground) and six liquid flavorings. For headspace analysis of alpha-diketones, we transferred bulk material into a sealed $40-\mathrm{mL}$ amber volatile organic analysis vial and let it rest for 24 hours at room temperature $\left(70^{\circ} \mathrm{F}\right)$ in the laboratory. Then $2 \mathrm{~mL}$ of headspace air was transferred to a $450-\mathrm{mL}$ canister and pressurized to approximately 1.5 times of atmospheric pressure. Using the canister analysis system, the concentrations were calculated in ppb of analytes in the headspace.

\section{Continuous (Real-time) Air Sampling}

We used a RAE Systems (San Jose, CA) ppbRAE 3000 (Model \#PGM-7340) monitor to measure levels of total VOCs in the air. This sampling was conducted to identify areas where coffee or flavorings could be releasing VOCs. Areas with higher release of VOCs may be targets for sampling for alpha-diketones and for exposure controls. We also collected continuous measurements of $\mathrm{CO}_{2}, \mathrm{CO}$, temperature (in ${ }^{\circ} \mathrm{F}$ ), and relative humidity using a TSI Incorporated (Shoreview, MN) VelociCalc Model 9555-X Multi-Function Ventilation Meter equipped with a Model 982 IAQ probe. 
Musty Odor Assessment

On February 4, 2016, we visually inspected for water incursion and mold growth in areas above ceiling tiles in the owner's office with reported musty odors and a second floor storage area above the office areas. We also inspected for sources of water incursion above the ceiling tiles in the restroom and in the hallway of the administrative area.

\section{Exposure Limits}

Occupational Safety and Health Administration (OSHA)

The U.S. Department of Labor's OSHA permissible exposure limits (PELs) and STELs are legal limits that are enforceable in workplaces covered under the Occupational Safety and Health Act. OSHA PELs represent the legal maximum TWA exposure to a physical or chemical agent during any 8-hour work shift of a 40-hour workweek [OSHA 2016]. OSHA STELs are the legal maximum average exposure for a 15-minute time period. Some chemicals also have an OSHA ceiling value which represent levels that must not be exceeded at any time. For some chemicals, OSHA has also established an Immediately Dangerous to Life or Health (IDLH) value. An IDLH value is a concentration of an air contaminant that can cause death or immediate or delayed permanent adverse health effects, or prevent escape from such an environment. Currently, there are no PELs for diacetyl, 2,3-pentanedione, or 2,3-hexanedione. For substances for which an OSHA PEL has not been issued, violation of the OSHA General Duty Clause can be considered using available occupational exposure references and recommendations [OSHA 1993; OSHA 2003].

\section{American Conference of Governmental Industrial Hygienists (ACGIH)}

ACGIH is a professional, not-for-profit scientific association that reviews existing published, peer-reviewed scientific literature and publishes recommendations for levels of substances in air based on an 8-hour workday and 40-hour workweek. These recommendations are called threshold limit values (TLVs $\left.{ }^{\circledR}\right)$ [ACGIH 2016]. ACGIH TLVs are not standards; they are health-based guidelines derived from scientific and toxicological information. ACGIH provides TLV-TWA guidelines that are levels that should not be exceeded during any 8-hour workday of a 40-hour workweek. ACGIH also provides TLV-STEL guidelines which are 15-minute exposure levels that should not be exceeded during a workday. Exposures above the TLV-TWA but less than the TLV-STEL should be (1) less than 15 minutes, (2) occur no more than four times a day, and (3) be at least 60 minutes between exposures [ACGIH 2016]. Additionally, ACGIH provides TLV-Ceiling values which are levels that should not be exceeded at any time during a work shift.

\section{National Institute for Occupational Safety and Health (NIOSH)}

NIOSH provides RELs as TWA concentrations that should not be exceeded over an 8- or 10-hour work shift, during a 40-hour workweek [NIOSH 2010]. NIOSH also provides STELs which are 15-minute TWA exposures that should not be exceeded [NIOSH 2010]. Some chemicals have ceiling values which are concentrations that should not be exceeded during any time [NIOSH 2010]. For some chemicals, NIOSH has IDLH values. Currently, NIOSH has RELs and STELs for diacetyl and 2,3-pentanedione. NIOSH does not have a REL or a STEL for 2,3-hexanedione. NIOSH does not have ceiling limits or IDLH values for diacetyl, 2,3-pentanedione, or 2,3-hexanedione. 
For diacetyl and 2,3-pentanedione, the NIOSH RELs are 5.0 ppb and $9.3 \mathrm{ppb}$, respectively, as a TWA for up to a 8-hour workday during a 40-hour workweek (Table 1). The NIOSH STELs are $25 \mathrm{ppb}$ for diacetyl and $31 \mathrm{ppb}$ for 2,3-pentanedione [NIOSH 2016]. The NIOSH exposure standards do not differentiate between natural and synthetic chemical origin of diacetyl or 2,3-pentanedione. Although the NIOSH exposure limits for 2,3-pentanedione is above that of diacetyl, 2,3-pentanedione has been shown to be as hazardous as diacetyl [Hubbs et al. 2012; Morgan et al. 2012]. The hazard potential probably increases when these chemicals occur in combination with each other; having exposure to chemicals with the same functional alpha-diketone group and effect on the same system or organ (e.g., lungs) can result in additive effects [ACGIH 2016]. The NIOSH REL is higher for 2,3-pentanedione than for diacetyl largely because analytic measures were not available in a validated OSHA method to detect 2,3-pentanedione at lower levels. In addition to the REL, NIOSH also recommends an action level (AL) for diacetyl of $2.6 \mathrm{ppb}$ to be used with exposure monitoring in an effort to ensure employee exposures are routinely below the diacetyl REL of $5 \mathrm{ppb}$ [NIOSH 2016].

Table 1. Exposure limits for compounds sampled during the NIOSH survey, February 2016

\begin{tabular}{|c|c|c|c|c|c|c|}
\hline \multirow{2}{*}{ Compound } & \multirow{2}{*}{$\begin{array}{c}\text { OSHA* } \\
\text { PEL }\end{array}$} & \multicolumn{2}{|c|}{ ACGIH } & \multicolumn{3}{|c|}{ NIOSH } \\
\hline & & TLV & STEL & REL & STEL & IDLH \\
\hline Diacetyl & - & $10 \mathrm{ppb}$ & $20 \mathrm{ppb}$ & $5 \mathrm{ppb} \dagger$ & $25 \mathrm{ppb}$ & - \\
\hline 2,3-Pentanedione & - & - & - & $9.3 \mathrm{ppb}^{\dagger}$ & $31 \mathrm{ppb}$ & - \\
\hline 2,3-Hexanedione & - & - & - & - & - & - \\
\hline Carbon dioxide & $5,000 \mathrm{ppm}$ & $5,000 \mathrm{ppm}$ & $30,000 \mathrm{ppm}$ & $5,000 \mathrm{ppm}$ & $30,000 \mathrm{ppm}$ & $40,000 \mathrm{ppm}$ \\
\hline Carbon monoxide & $50 \mathrm{ppm}$ & $25 \mathrm{ppm}$ & - & $35 \mathrm{ppm}$ & $\begin{array}{c}200 \mathrm{ppm} \\
\text { (ceiling limit)§ }\end{array}$ & $1,200 \mathrm{ppm}$ \\
\hline
\end{tabular}

Note: OSHA: Occupational Safety and Health Administration; ACGIH: American Conference of Governmental Industrial Hygienists; NIOSH: National Institute for Occupational Safety and Health; PEL: permissible exposure limit; STEL: short-term exposure limit; TLV: threshold limit value; REL: recommended exposure limit; IDLH: immediately dangerous to life or health; ppb: parts per billion; ppm: parts per million; "_,": no exposure limit available.

*There are no OSHA STEL or IDLH values for the compounds in the table.

$\dagger$ The NIOSH RELs for diacetyl and 2,3-pentanedione are time-weighted averages for up to an 8-hour day, during a 40-hour workweek.

†OSHA and NIOSH limits are designed for occupational exposure measurements in manufacturing and other trades that have potential sources of carbon dioxide or carbon monoxide (e.g., coffee roasting, welding, vehicle exhaust, diesel engine exhaust). Typical levels of carbon monoxide in offices are 0-5 ppm. In office settings, carbon dioxide generally should not be greater than $700 \mathrm{ppm}$ above outdoor carbon dioxide levels; this typically corresponds to indoor concentrations below $1200 \mathrm{ppm}$.

§This is the NIOSH ceiling exposure limit $(200 \mathrm{ppm})$ for carbon monoxide. A ceiling concentration should not be exceeded at any time. 


\section{Medical Survey \\ Participants}

We invited all current employees and the owner to participate in the medical survey at the workplace on February 4, 2016. Participation was voluntary; written informed consent was obtained from each participant at the time of testing. The survey included, in the order performed, a medical and work history questionnaire, quantification of exhaled nitric oxide, impulse oscillometry, spirometry, and administration of bronchodilator with repeat impulse oscillometry and spirometry (if indicated).

\section{Questionnaire}

We used an interviewer-administered computerized questionnaire to ascertain symptoms and diagnoses, work history with the current company and other coffee or flavoring companies, and cigarette smoking history. Questions on respiratory health were derived from five standardized questionnaires - the European Community Respiratory Health Survey [Burney et al. 1994; ECRHS 2014], the American Thoracic Society adult respiratory questionnaire (ATS-DLD-78) [Ferris 1978], the International Union Against Tuberculosis and Lung Disease [Burney et al. 1987, 1989], and the Third National Health and Nutrition Examination Survey (NHANES) [CDC 1996] and NHANES 2007-2012 questionnaires [NCHS 2015] and were supplemented with additional respiratory and systemic symptom questions.

\section{Spirometry}

The purpose of the spirometry test is to determine a person's ability to move air in and out of their lungs. Test results are compared to expected normal values. The test includes measurements of the forced vital capacity (FVC) (the total amount of air the participant can forcefully blow out after taking a deep breath) and the 1-second forced expiratory volume (FEV1) (the amount of air that the participant can blow out in the first second of exhaling) and the calculation of the ratio of FEV1 to FVC. We used American Thoracic Society criteria for acceptability and repeatability [Miller et al. 2005].

We used a volume spirometer to measure exhaled air volume and flow rates. We used equations for predicted values and lower limits of normal derived from NHANES III data to define abnormal spirometry [Hankinson et al. 1999]. We defined obstruction as an FEV1/ FVC ratio less than the lower limit of normal with FEV1 less than the lower limit of normal; restriction as a normal FEV1/FVC ratio with FVC less than the lower limit of normal; and mixed obstruction and restriction as having FEV1, FVC, and FEV1/FVC ratio all less than the lower limit of normal. We used the FEV1 percent predicted to categorize such abnormalities as mild, moderate, moderately severe, severe, or very severe [Pellegrino et al. 2005].

\section{Impulse Oscillometry}

The purpose of the impulse oscillometry (IOS) test is to measure certain properties of the airways that affect respiratory airflow (described below). Many occupational lung diseases involve the small airways; however, this part of the lung is difficult to evaluate. Oscillometry is a useful technology to understand the effects of occupational exposures on the small airways. This test is conducted using regular breathing and does not require a forceful exhalation. There are no contraindications or side effects to the test [Smith et al. 2005]. 
Spirometry can be normal despite respiratory symptoms or evidence of small airways disease on lung biopsy [King et al. 2011; Oppenheimer et al. 2007]; therefore, oscillometry results complement spirometry and can be used even when spirometry is not possible because of a contraindication. Abnormalities in IOS values can indicate airways obstruction or blockage of air flow through the airways. In addition, IOS might be able to better detect small airways obstruction than spirometry in people with asthma and chronic obstructive pulmonary disease [Brashier and Salvi 2015; Smith et al. 2005].

We used an IOS machine (CareFusion Corp., San Diego, CA) to measure resistance (R), the energy required to propagate the pressure wave through the airways, and reactance (X), which reflects the viscoelastic properties of the respiratory system. The IOS testing machine sends sound waves called pressure oscillations at different frequencies (e.g., 5 hertz (Hz) and $20 \mathrm{~Hz}$ ) into the airways to measure how airways respond to these small pressures. The test calculates (1) the airway resistance at different frequencies including $5 \mathrm{~Hz}$ (R5) and $20 \mathrm{~Hz}$ (R20), (2) the reactance at different frequencies including $5 \mathrm{~Hz}$ (X5), (3) resonance frequency (Fres) which is the frequency where there is no airway reactance, and (4) the total reactance (AX) at all frequencies between $5 \mathrm{~Hz}$ and the Fres. The predicted values for $\mathrm{R}$ and $\mathrm{X}$ were based on sex and height according to references values recommended by the manufacturer.

\section{Bronchodilator Reversibility Testing for Impulse Oscillometry and Spirometry}

If a participant had abnormal spirometry or IOS, we repeated the spirometry and IOS tests after the participant received a bronchodilator inhaler medication (i.e., albuterol), which can open the airways in some individuals (e.g., asthmatics). For spirometry, we defined reversibility (improvement) as increases of at least $12 \%$ and $200 \mathrm{~mL}$ for either FEV1 or FVC after bronchodilator administration. For IOS, we defined reversibility (improvement) as a decrease of at least $20 \%$ of either Fres or R5 or a decrease of $40 \%$ for AX.

\section{Exhaled Nitric Oxide}

We used the NIOX MINO ${ }^{\circledR}$ device (Aerocrine Inc., Morrisville, NC) to measure the amount of nitric oxide in the air that the participant breathed out. Nitric oxide is a gas that is produced by the airways, and elevated levels can be a sign of eosinophilic airway inflammation in asthma [Dweik et al. 2011]. In adults, fractional nitric oxide concentration in exhaled breath levels above $50 \mathrm{ppb}$ are considered elevated. In adults with asthma, elevated levels might indicate that their asthma is uncontrolled [Dweik et al. 2011].

\section{Statistical Analysis}

For the air sampling data, we calculated the mean sampling duration in minutes, the percent of samples above the LOD, and the minimum and maximum air concentration of diacetyl, 2,3-pentanedione, and 2-3, hexanedione measured. All analyses of air sampling data were performed using SAS software, Version 9.3 (SAS Institute Inc., Cary, NC). Values presented in the report from samples below the LOD are denoted by a "<" symbol. For the ventilation assessment, calculations were performed using Excel ${ }^{\circledR} 2013$ (Microsoft ${ }^{\circledR}$, Redmond, WA). 


\section{Results}

All results tables are located in Appendix A.

\section{Ventilation Assessment Results}

During our assessment, the outdoor temperatures were lower than average; thus, the ventilation system was not on. On February 1, 2016, temperature on the office side of the facility ranged from $70.4^{\circ} \mathrm{F}$ to $72.1^{\circ} \mathrm{F}$. The temperature in the production room was $69.8^{\circ} \mathrm{F}$, and the warehouse was $67.8^{\circ} \mathrm{F}$. The $\mathrm{CO}$ measurements taken during the ventilation assessment were generally low and ranged from 0.1 parts per million ( $\mathrm{ppm}$ ) to $0.3 \mathrm{ppm}$ in the front office areas, $0.6 \mathrm{ppm}$ in the production room, and $0.5 \mathrm{ppm}$ in the warehouse. $\mathrm{CO}_{2}$ levels during the ventilation assessment were $520 \mathrm{ppm}$ in the warehouse and $715 \mathrm{ppm}$ in the production room. In the front office areas, $\mathrm{CO}_{2}$ levels ranged from $709 \mathrm{ppm}$ in the showroom area to $927 \mathrm{ppm}$ in the kitchen. The highest $\mathrm{CO}_{2}$ measurement was in the restroom $(1,002 \mathrm{ppm})$. The $\mathrm{CO}$ and $\mathrm{CO}_{2}$ levels measured outside on February 1, 2016 were zero ppm and 357 ppm, respectively.

Ventilation to the facility is provided by one Ruud (Fort Smith, AR) Model UJKA-A042CK rooftop heat pump and one AdobeAir (Phoenix, AZ) Model ED630G rooftop ducted evaporative cooler. The heat pump system appeared to be ducted as a $100 \%$ air recirculation system that provides no fresh, outdoor air to occupied spaces of the facility. The evaporative cooler only provides fresh, outdoor air when the unit is operated.

Air flow measurements of supply vents and exhaust outlets were taken with the Ruud heat pump system off (as it was found during our visit) and after turning the unit on. While the rooftop heat pump did not contain ventilation filters, $20^{\prime \prime} \times 20^{\prime \prime} \times 1$ " pleated air filters were in place directly behind the return grilles leading back to the unit. With the heat pump unit operating, there was adequate air flow to and from all occupied areas on the office side and the production spaces of the facility. However, in the current configuration, those spaces were not receiving any outdoor air from the mechanical ventilation system. Based on our measurements of air flow, calculations show that as little as $10 \%$ outdoor air would meet the outdoor air requirements set forth in American National Standards Institute (ANSI)/ASHRAE Standard 62.1-2003 Ventilation for Acceptable Indoor Air Quality [ANSI/ASHRAE 2016] for typical occupancy levels in the office areas. Up to $20 \%$ outdoor air would need to be supplied by the ventilation system to meet ASHRAE recommendations in the production spaces. During much of the year, when the warehouse bay and main doors are open, this outdoor air could be provided by natural ventilation. Otherwise, the outdoor air could be provided through the rooftop evaporative cooler.

The Wizard Stick generated visible fog that showed there was limited air movement between the front office areas and the production room. Air in the warehouse flowed toward the bay door and exterior doorway. During inspection of the rooftop unit we learned that the system was configured for re-circulation of air in the office areas and production room with no fresh air supply. A visual assessment of the return air interior duct work in the office areas showed little dust accumulation, and the filters over the return openings were clean. 
During warm weather, a mobile evaporative unit in the warehouse is used to help cool the space [Master Cool] in addition to the rooftop ducted evaporative cooler. There was visible accumulation of mineral deposits on the rooftop evaporative cooler and on the mobile unit in the warehouse.

During our inspection on the roof, we noted that the roaster exhaust stack was partially plugged with chaff and debris (Figure 1).

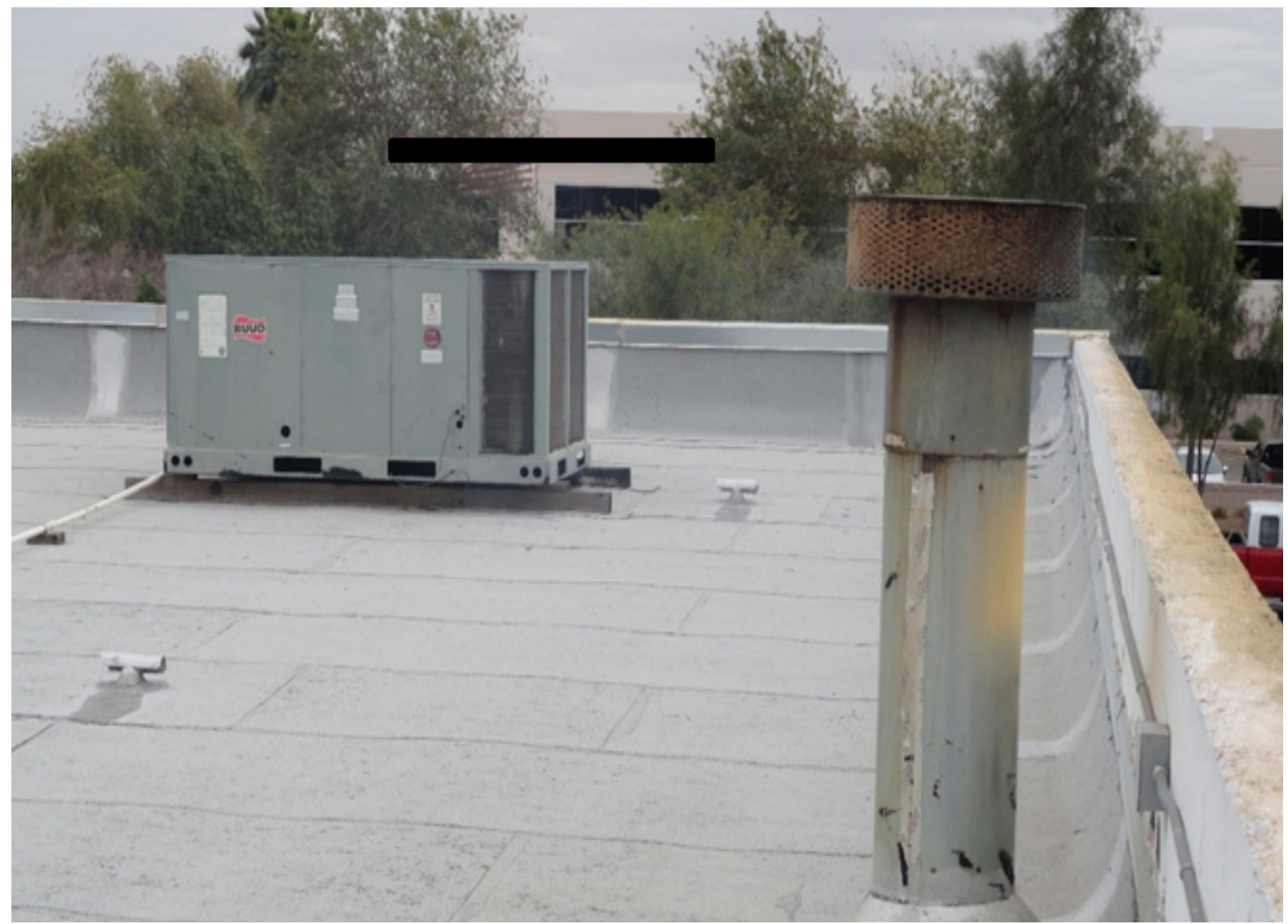

Figure 1. Roaster exhaust stack partially obstructed by chaff and debris, NIOSH survey, February 2016.

We also noted a smell arising from a container inside a cabinet in the showroom that held drain contents from an espresso machine.

\section{Industrial Hygiene Survey}

\section{Personal and Area Full-shift TWA Air Sampling Results}

OSHA Methods 1013/1016

Table A1 presents the personal and area full-shift TWA air concentrations by location using OSHA Methods 1013/1016. We collected five personal and 16 area full-shift TWA air samples. None of the personal air samples were above the NIOSH RELs of 5 ppb diacetyl or 9.3 ppb 2,3-pentanedione. 
One area air sample was above the NIOSH REL for diacetyl. The area sample taken outside on the first day of sampling had the highest air concentration of diacetyl (14.1 ppb) and was below the LOD for 2,3-pentanedione. This area air sample was located near the building's corner pillar under an overhanging roof, near the front door entrance to the facility. On the second day of sampling, the outside area air sample was below the LOD for diacetyl and 2,3-pentanedione. NIOSH RELs are intended to be directly compared to personal TWA measurements; therefore, an area air sample that exceeds a NIOSH REL is only an indication of potential personal exposures.

\section{Evacuated Canister Method}

Table A2 presents the area full-shift TWA air concentrations by location using the canister method. We collected 16 area full-shift TWA air samples using evacuated canisters. Three area air samples were above the NIOSH REL for diacetyl. The area sample taken in the showroom had the highest air concentration of diacetyl (19.0 ppb). The area sample taken on the syrup storage racks in the warehouse on the first day of sampling had the second highest air concentration of diacetyl $(9.0 \mathrm{ppb})$. The desk near the roasting area on the first day of sampling had an air concentration of diacetyl just above the NIOSH REL (6.0 ppb). The sample taken in the grinding/flavoring area on the first day had an air concentration of 4.8 ppb, which is just below the NIOSH REL. All area air samples using evacuated canisters were below the NIOSH REL for 2,3-pentanedione. As noted above, NIOSH RELs are intended to be directly compared to personal TWA measurements; therefore, an area air sample that exceeds a NIOSH REL is only an indication of potential personal exposures.

\section{Personal Task Air Sampling Results}

Table A3 presents the personal air concentrations by task. We collected 25 personal task air samples using OSHA Methods 1013/1016. Task duration ranged from 3 minutes to 55 minutes, with a median of 11 minutes. An employee packaging coffee, specifically packaging ground French Roast in small foil bags, had the highest task exposure to diacetyl (39.5 ppb), and this task lasted 55 minutes. An employee grinding flavored coffee beans had the second and third highest task exposures to diacetyl (18.5 ppb and $15.2 \mathrm{ppb})$, and these tasks lasted 24 minutes and 20 minutes, respectively.

We measured the highest task exposure to 2,3-pentanedione on an employee flavoring roasted coffee beans (23.6 ppb) during a task that lasted 15 minutes. An employee packaging French Roast in small foil bags had the second highest task exposure to 2,3-pentanedione (19.0 ppb). The next three highest task exposures to 2,3-pentanedione were measured on an employee working with flavorings $(17.0 \mathrm{ppb}$ and $14.0 \mathrm{ppb}$ while grinding flavored coffee beans and $15.7 \mathrm{ppb}$ while flavoring roasted coffee beans, during tasks lasting 20 minutes, 24 minutes, and 8 minutes, respectively).

\section{Instantaneous Evacuated Canister Air Sampling Results}

Table A4 presents the instantaneous evacuated canister concentrations. We collected 10 personal (near the breathing zone of an employee) and two source (during simulations of tasks) 
instantaneous air samples using evacuated canisters. The instantaneous sample collected during grinding of roasted coffee beans that had been decaffeinated using the methylene chloride method resulted in a diacetyl air concentration of 8,523.7 ppb and a 2,3-pentanedione air concentration of 4,693.3 ppb. The second highest diacetyl and 2,3-pentanedione air concentrations were obtained from inside a roasted bean storage bin during a simulation of removing the lid from the bin, then stirring over-roasted beans (French Roast) with a scoop, with a diacetyl air concentration of 7,385.7 ppb and a 2,3-pentanedione air concentration of 1,749.2 ppb. A second instantaneous sample obtained during a simulation of scooping roasted beans (Italian Roast) in a storage bin resulted in a diacetyl air concentration of $214.5 \mathrm{ppb}$ and a 2,3-pentanedione air concentration of $107.9 \mathrm{ppb}$. These two simulation instantaneous samples are not necessarily representative of potential employee exposures as the sampling probe was not near the breathing zone of an employee.

The two instantaneous samples taken during packing of French Roast coffee resulted in diacetyl air concentrations ranging from $39.5 \mathrm{ppb}$ to $365.4 \mathrm{ppb}$ and 2,3-pentanedione air concentrations from $20.1 \mathrm{ppb}$ to $191.8 \mathrm{ppb}$.

The six instantaneous samples taken during the roasting process resulted in diacetyl air concentrations ranging from $1.5 \mathrm{ppb}$ to $9.0 \mathrm{ppb}$ and 2,3-pentanedione air concentrations ranging from below the LOD to $5.7 \mathrm{ppb}$.

Our measurement of methylene chloride in the instantaneous sample taken while grinding French Roast beans that had been decaffeinated using the methylene chloride method was less than the LOD $(<0.37 \mathrm{ppb})$.

\section{Overnight Evacuated Canister Air Sampling Results}

The two overnight canisters sampled the air for about 15 hours each, from approximately 4:30 p.m. to 7:30 a.m. One overnight canister was on the desk in the roasting area, and the other overnight canister was on a shelf in the warehouse. For the roasting area desk, the overnight diacetyl air concentration was $1.9 \mathrm{ppb}$ and the 2,3-pentanedione air concentration was $1.1 \mathrm{ppb}$. For the warehouse, the overnight diacetyl air concentration was $1.0 \mathrm{ppb}$ and the 2,3-pentanedione air concentration was $0.5 \mathrm{ppb}$.

\section{Bulk Samples and Headspace Results}

Table A5 presents the headspace results for the bulk samples of roasted coffee beans and liquid flavorings. The highest concentration of diacetyl $(2,409 \mathrm{ppb})$ was associated with the over-roasted French Roast beans that had been in a storage bin for three days. The highest concentration of 2,3-pentanedione $(47,848 \mathrm{ppb})$ was associated with the cinnamon nut crème liquid flavoring.

Continuous (Real-time) Volatile Organic Compounds, Carbon Dioxide, and Carbon Monoxide Monitoring Results

Figures 2-5 display the average total VOCs measured at various locations and during various tasks. 
Figure 2 displays the continuous VOC monitoring results in the production room, next to the roaster and near packaging, on February 2, 2016. As the figure depicts, the average total VOCs increased steadily in the morning while roasting was occurring. After the roaster was turned off mid-day, the average total VOCs sharply increased until the roaster was turned back on, after which they decreased. This sharp increase coincided in time with flavoring of roasted beans and grinding of flavored beans in the adjacent warehouse. In the afternoon, roasting again occurred in the production room and packaging of unflavored beans occurred in the packaging area of the production room. Also in the afternoon, grinding of unflavored beans and flavoring of roasted beans occurred in the adjacent warehouse.

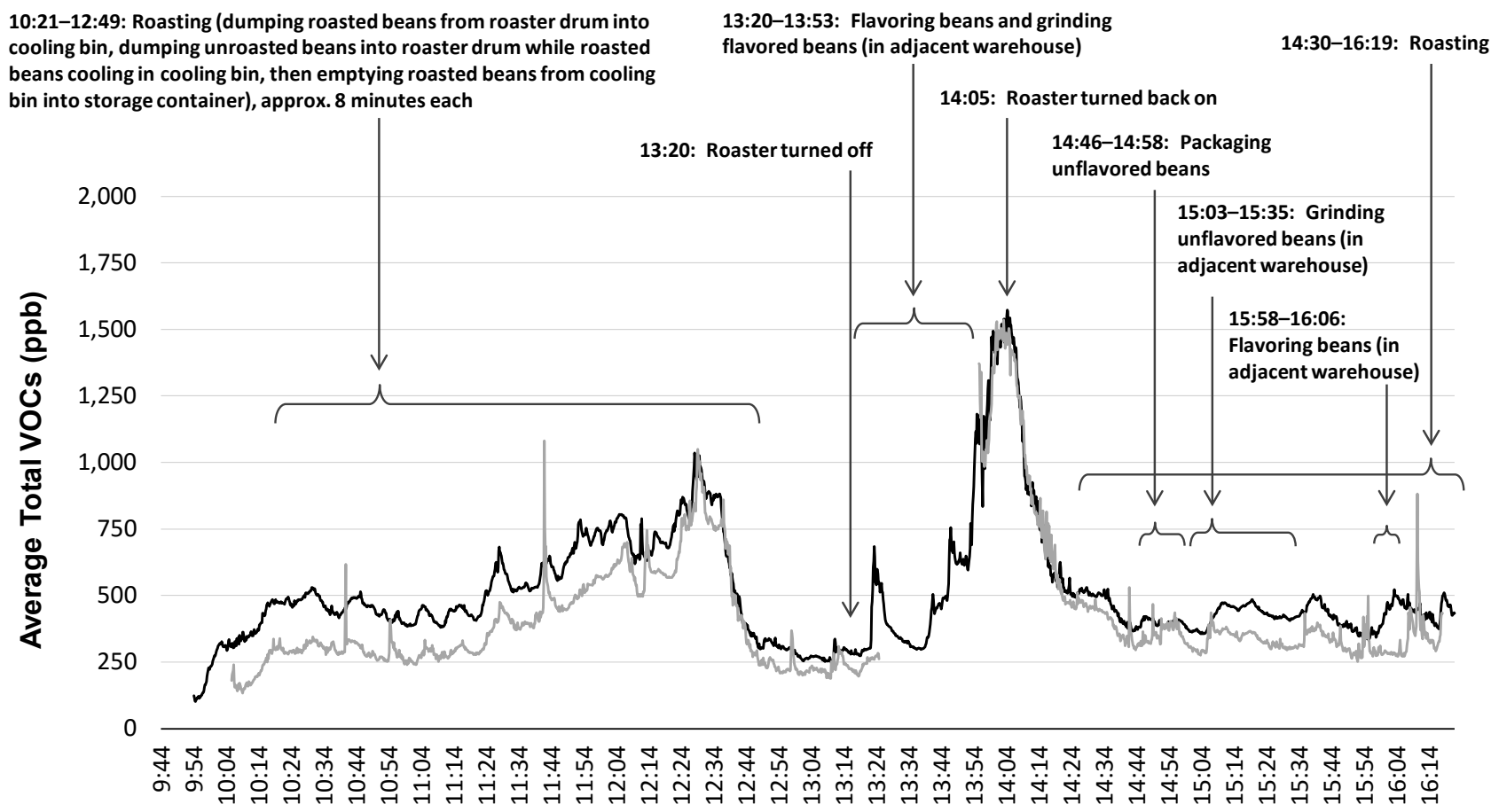

Time of Day

- Next to roaster — Near packaging

Figure 2. Continuous monitoring results of average total VOCs in the production room, next to the roaster (black line) and near packaging (grey line), NIOSH survey, February $2,2016$. 
Figure 3 displays the continuous VOC monitoring results near the grinding/flavoring area in the warehouse on February 2, 2016. We observed the highest levels of average total VOCs near the breathing zone of an employee grinding amaretto-flavored beans, reaching a peak of 38,560 ppb. Average total VOCs in the grinding/flavoring area (not in the employee's breathing zone) were lower, though increases were apparent while flavored beans were being ground, with levels reaching a peak of 5,282 ppb. Peak average total VOCs measured near the breathing zone of an employee flavoring roasted beans with amaretto liquid was 3,778 ppb.

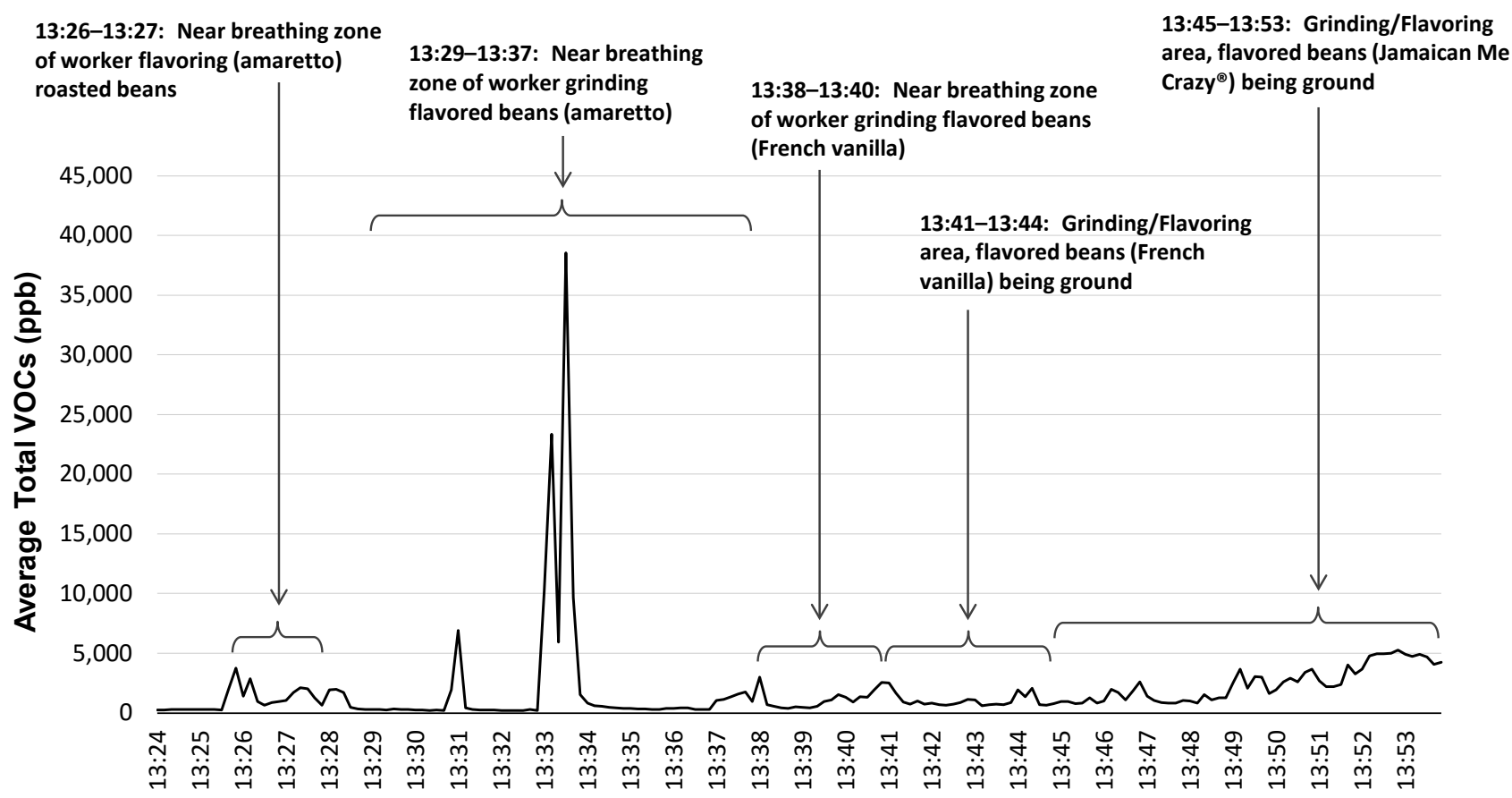

Time of Day

Figure 3. Continuous monitoring results of average total VOCs near the grinding/flavoring area in the warehouse, NIOSH survey, February 2, 2016. 
Figure 4 displays continuous VOC monitoring results in the production room, next to the roaster, on February 3, 2016. Similar to the previous day's measurements at the same location, the average total VOCs increased steadily while roasting was occurring until a decrease in the afternoon. We do not know when, or if, the roaster was turned off on this day. Two periods of increasing average total VOCs coincided with, though might not have been caused by, flavoring of roasted beans and grinding of flavored beans in the adjacent warehouse. The period of lower average total VOCs in the afternoon coincided in time with, though might not have been caused by, grinding of unflavored beans in the adjacent warehouse.

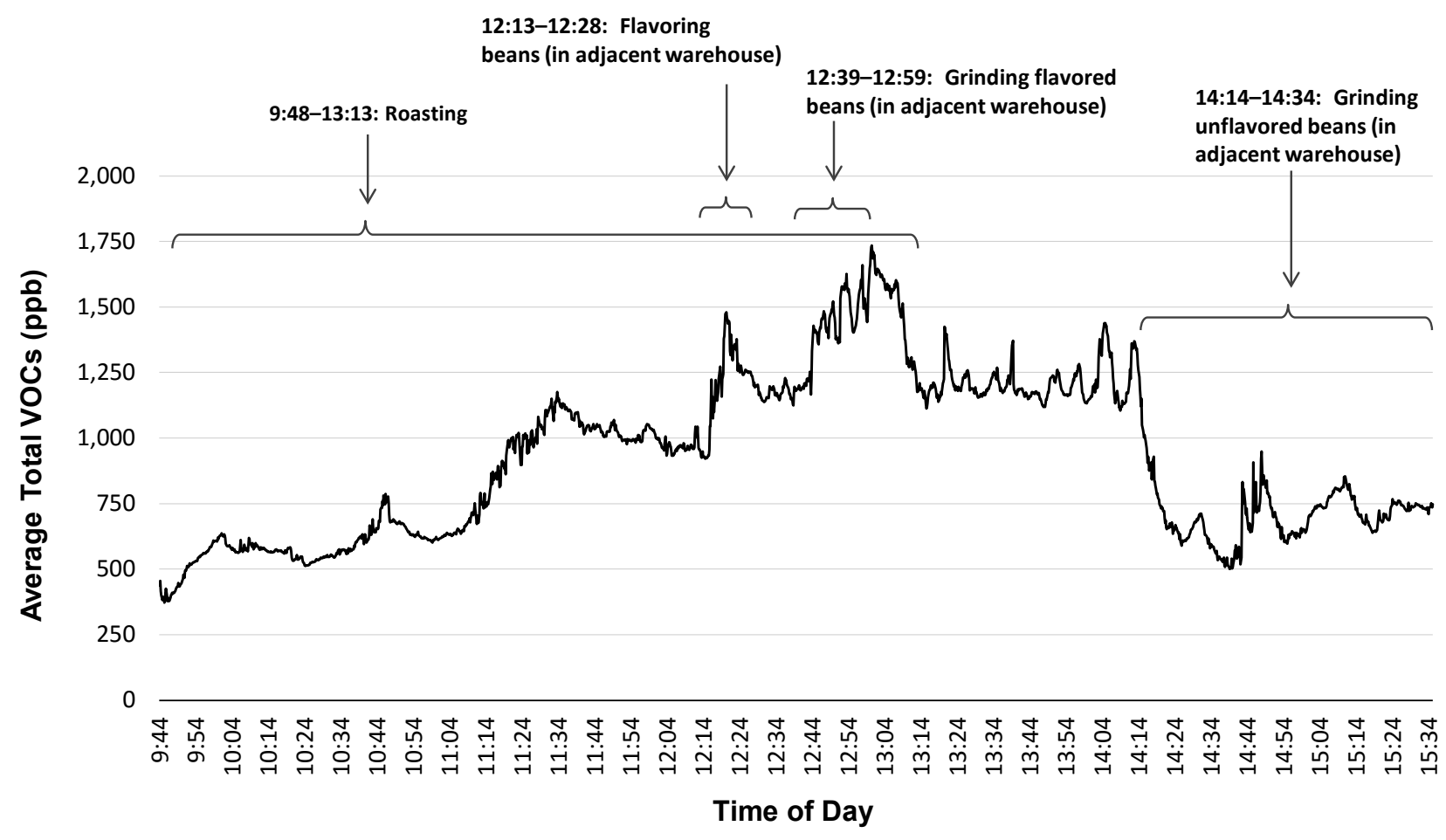

Figure 4. Continuous monitoring results of average total VOCs in the production room next to the roaster, NIOSH survey, February 3, 2016. 
Figure 5 displays continuous VOC monitoring results in the production room on February 4, 2016. On this day, the ppbRAE 3000 instrument was held at various sources of VOCs, specifically at the lip of open storage bins containing various types of roasted beans. These source-based measurements are not representative of employee exposures as the sampling probe was not near the breathing zone of an employee. We observed the highest average total VOCs when the instrument was held at the lip of an open bin containing Italian Roast, with levels reaching a peak of 33,394 ppb. The second highest average total VOCs was recorded when the instrument was held at the lip of an open bin that contained over-roasted French Roast and had not been opened in over one day, with levels reaching a peak of 18,209 ppb.

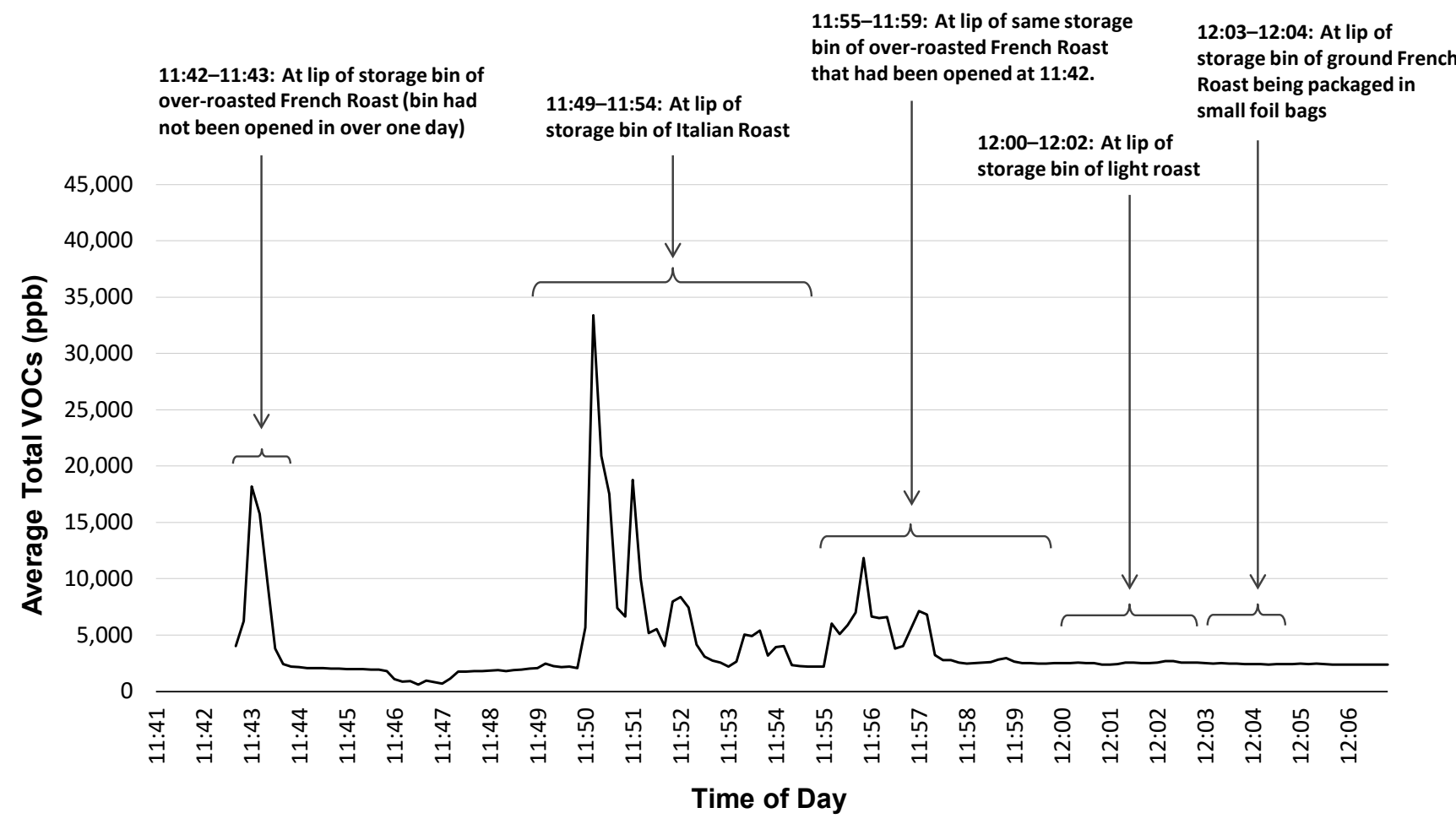

Figure 5. Continuous monitoring results of average total VOCs in the production room, NIOSH survey, February 4, 2016. 
Figure 6 displays the continuous $\mathrm{CO}_{2}$ levels sampled during the site visit. On the first day of sampling, February 2, 2016, a VelociCalc was placed in the production room, next to the roaster, for the entire day, and $\mathrm{CO}_{2}$ levels ranged from $398 \mathrm{ppm}$ to $835 \mathrm{ppm}$. On February 3 , 2016, the VelociCalc was first placed in the shared office and later moved to the production room next to the roaster. In the shared office, the $\mathrm{CO}_{2}$ levels ranged from $620 \mathrm{ppm}$ to 1,102 ppm. In the production room, the $\mathrm{CO}_{2}$ levels ranged from $428 \mathrm{ppm}$ to $788 \mathrm{ppm}$. On February 4,2016 , the three major peaks in $\mathrm{CO}_{2}$ levels correspond to holding the VelociCalc at the lip of open storage bins containing over-roasted French Roast (1,507 ppm), Italian Roast (2,284 ppm), and ground French Roast being packaged into small foil bags (1,889 ppm).

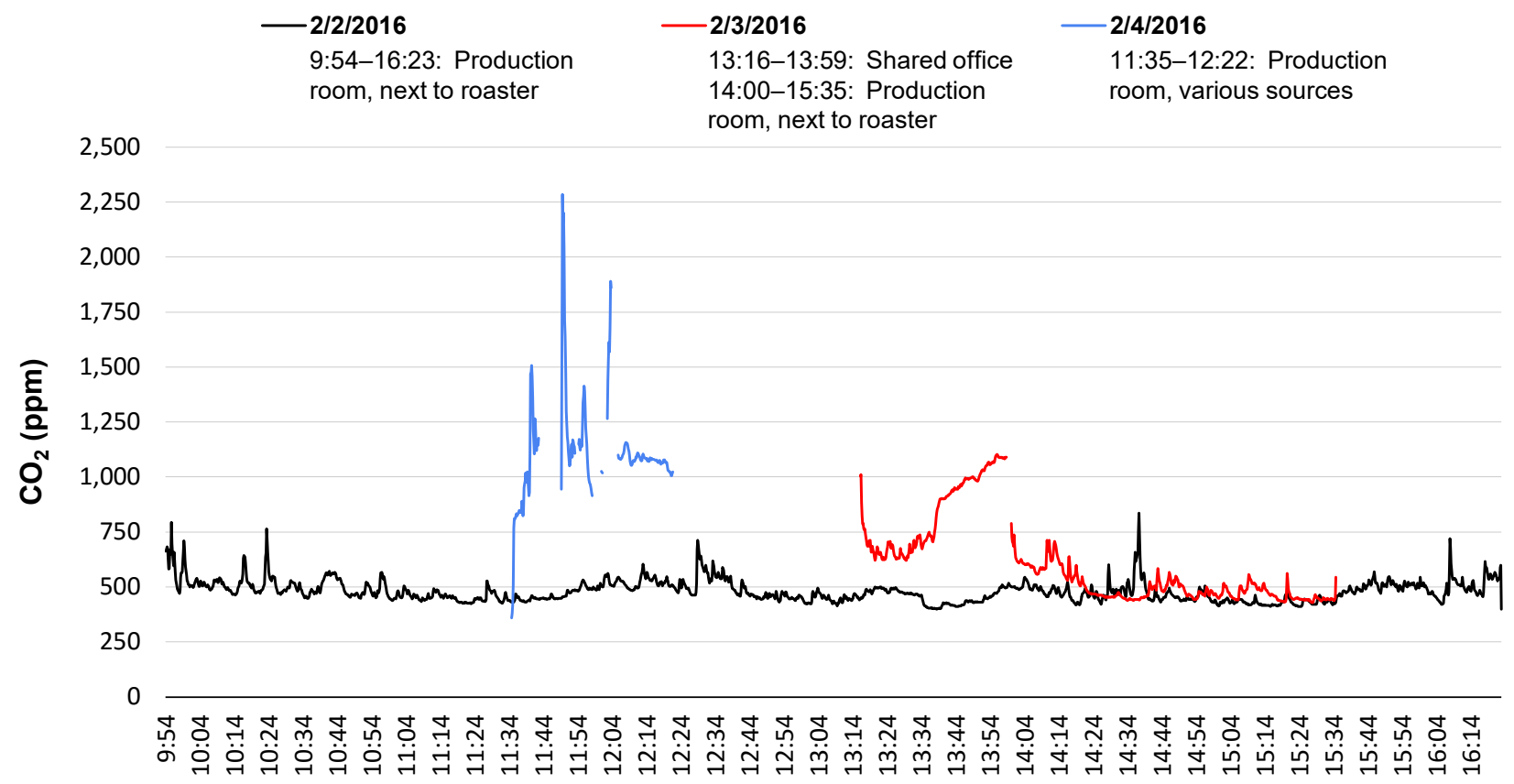

Time of Day

Figure 6. Continuous monitoring results of $\mathrm{CO}_{2}$ in the production room, next to the roaster (black line), in the shared office and the production room (red line), and near the lips of various bins containing roasted beans (blue line), NIOSH survey, February 2-4, 2016. 
Figure 7 displays the continuous CO levels sampled during the site visit. On February 2, 2016 in the production room, next to the roaster, the CO levels ranged from zero ppm to 3.7 ppm. On February 3, 2016, the CO levels ranged from zero ppm to $1.5 \mathrm{ppm}$ in the shared office and from zero ppm to $2.7 \mathrm{ppm}$ in the production room, next to the roaster. On February 4, 2016, the three major peaks in CO levels correspond to holding the VelociCalc at the lip of open storage bins containing over-roasted French Roast (223.1 ppm), Italian Roast (223.7 ppm), and ground French Roast being packaged into small foil bags (184.8 ppm).

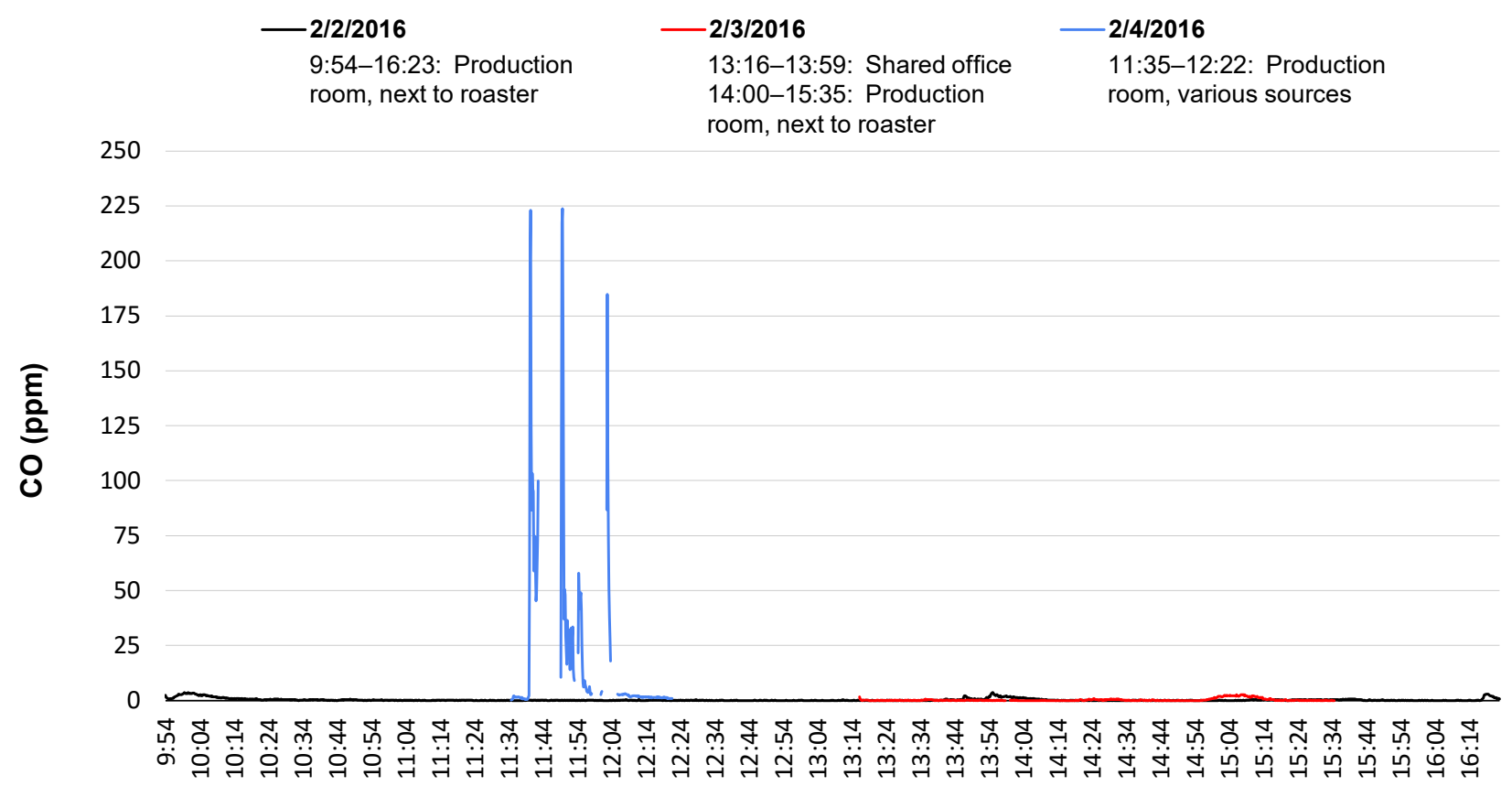

Time of Day

Figure 7. Continuous monitoring results of $\mathrm{CO}$ in the production room, next to the roaster (black line), in the shared office and the production room (red line), and near the lips of various bins containing roasted beans (blue line), NIOSH survey, February 2-4, 2016. 


\section{Musty Odor Assessment}

During the ventilation assessment, we noticed water stains on the ceiling tiles around the return register vents in the hallway of the office areas as well as around the exhaust fan above the toilet in the restroom (Figure 8).

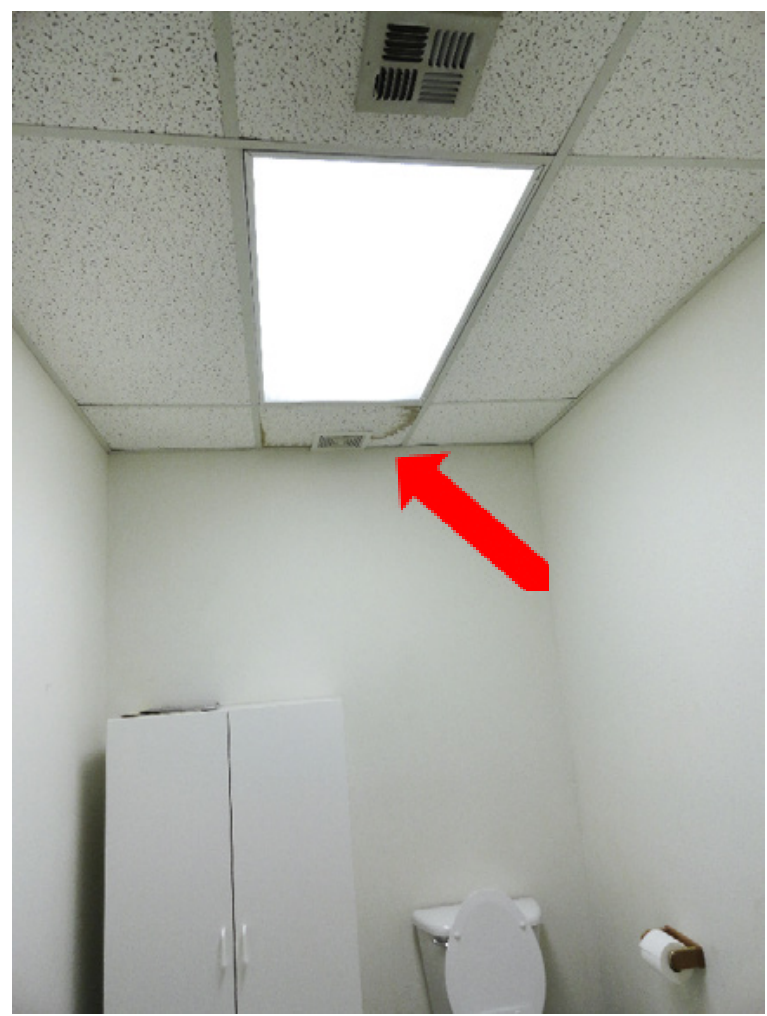

Figure 8. Water stain on the ceiling tiles around the exhaust fan above the toilet in the restroom, NIOSH survey, February 2016.

The owner reported periodically smelling a musty or mold odor in the main administrative (owner's) office. Upon further assessment above the ceiling tile in the owner's office, we found water staining on a wooden beam (Figure 9).

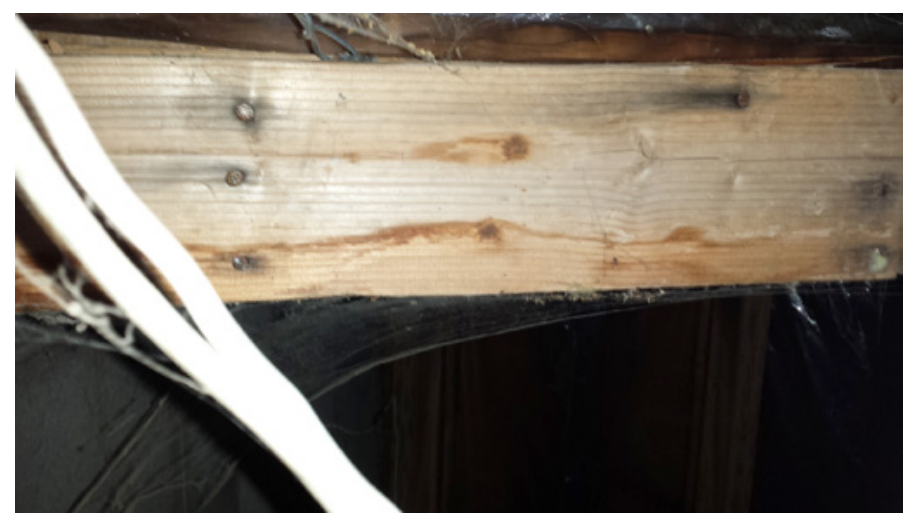

Figure 9. Water staining on a wooden beam above the ceiling tile in the owner's office, NIOSH survey, February 2016. 
There was no active leak source identified, but the beam felt damp to the touch. In addition, there was an accumulation of mouse droppings in the space above the ceiling tiles in the owner's office.

\section{Medical Survey}

All four employees (including the owner) participated in all aspects of the medical survey. Some participants reported respiratory symptoms. All participants had normal spirometry. Some participants had possible central airways abnormalities on IOS testing. These respiratory symptoms and IOS abnormalities are not specific to a particular respiratory problem or disease. They could be related to workplace exposures or to other factors. Because of the small number of participants and the need to protect individuals' privacy, we cannot provide more detailed results that would shed light on possible work-relatedness, such as health measures by job title or task. We mailed each participant their individual lung function test results with an explanation of the results and recommended each participant provide the information to their personal physician.

\section{Discussion}

Diacetyl, 2,3-pentanedione, 2,3-hexanedione, and other compounds such as $\mathrm{CO}_{2}$ and $\mathrm{CO}$ are naturally produced when coffee beans are roasted, and grinding the roasted coffee beans produces greater surface area for the off-gassing of these chemicals [Anderson et al. 2003; Akiyama et al. 2003; Daglia et al. 2007; Newton 2002; Nishimura et al. 2003; Raffel and Thompson 2013]. In addition, flavorings added to coffee can contain diacetyl or 2,3-pentanedione. Occupational exposure to diacetyl and 2,3-pentanedione can cause loss of lung function and the lung disease obliterative bronchiolitis [NIOSH 2016]. Some coffee processing employees developed obliterative bronchiolitis while working at a coffee processing facility that used flavorings and had elevated levels of diacetyl and 2,3-pentanedione throughout the facility [CDC 2013; Bailey et al. 2015; Duling et al. 2016]. Whether coffee processing employees at other facilities are at risk of lung disease from exposures to diacetyl, 2,3-pentanedione, and 2,3-hexanedione is not known.

At the coffee processing facility that is the subject of this report, we measured average air concentrations of diacetyl and 2,3-pentanedione to compare to the NIOSH RELs for these chemicals. All personal TWA air concentrations of diacetyl and 2,3-pentanedione were below the NIOSH RELs for diacetyl and 2,3-pentanedione. One area TWA air sample using the OSHA method was above the NIOSH REL for diacetyl, specifically outside on the first day. We observed that there was a strong smell of roasted coffee outside on the first day of sampling as well as a visible plume of exhaust from the roaster exhaust stack. These two factors could have contributed to the presence of diacetyl outside on this day. Although we cannot fully explain the higher diacetyl level outside on the first day of sampling, a high diacetyl level outside does not necessarily indicate exposures to diacetyl in the production area. Also, employees did not routinely occupy the area where the outside sampling equipment was located so these results are not directly reflective of employee exposures. In addition, NIOSH RELs are intended to be directly compared to personal TWA measurements; therefore, an 
area air sample that exceeds a NIOSH REL is only an indication of potential personal exposures.

Three area TWA air samples using the canister method were above the NIOSH REL for diacetyl: on the roasting area desk on the first day, in the warehouse on the syrup storage racks on the first day, and in the showroom. The canister method is partially validated [Lebouf et al. 2012] and not considered the standard method. We compare results to the NIOSH REL for informational purposes only. In addition, as noted above, NIOSH RELs are intended to be directly compared to personal TWA measurements; therefore, an area air sample that exceeds a NIOSH REL is only an indication of potential personal exposures.

We also measured diacetyl and 2,3-pentanedione during short-term tasks. The purpose of task air sampling was to understand what tasks have higher exposures to diacetyl and 2,3-pentanedione. Short-term peak exposures might have effects on the lungs even when full-shift average exposures are relatively low, as has been observed in the microwave popcorn industry [Kanwal et al. 2006]. There are no established occupational exposure limits for diacetyl and 2,3-pentanedione for short-term tasks that are shorter or longer in duration than 15 minutes. However, our task air sampling revealed that some tasks had higher air concentrations of diacetyl or 2,3-pentanedione than other tasks.

Packaging tasks had the highest air concentration of diacetyl and the second highest air concentration of 2,3-pentanedione. Among all packaging tasks measured, packaging ground French Roast in small foil bags accounted for the maximum diacetyl air concentration of $39.5 \mathrm{ppb}$, which exceeds the NIOSH STEL of $25 \mathrm{ppb}$ for diacetyl. This task had a duration of 55 minutes. Although the task duration was more than the 15-minute duration used to directly compare results to NIOSH STELs, these results indicate a likelihood of exceeding the NIOSH STEL for diacetyl during any 15-minute period of that task. The greater surface area for off-gassing in the ground French Roast coffee could have resulted in the higher air concentrations [Akiyama et al. 2003], whereas the other three packaging tasks sampled involved packaging of whole bean coffee.

The flavoring coffee task accounted for the highest air concentration of 2,3-pentanedione and an air concentration of diacetyl lower than the LOD. This task had a duration of 15 minutes, and the task's 2,3-pentanedione result of $23.6 \mathrm{ppb}$ does not exceed the NIOSH STEL of 31 ppb for 2,3-pentanedione. However, the STEL refers only to a single 15-minute exposure; we do not know the health effects of exposures at the level we measured when the task is repeated multiple times during a shift. If the flavoring manufacturer used 2,3-pentanedione as a substitute for diacetyl in the liquid flavorings, this would explain the finding of low diacetyl during the flavoring task. Although overall we measured lower levels of diacetyl than 2,3-pentanedione during flavoring, 2,3-pentanedione has been shown to have similar toxicity as diacetyl [Hubbs et al. 2012; Morgan et al. 2012; Morgan et al. 2016].

Diacetyl and 2,3-pentanedione task results for the roasting task were among the lowest we measured during the site visit. The roaster operator often remained near the roaster control panels, directly adjacent to the roaster cooling bin. The downdraft system on the roaster machine pulled air over the roasted beans and down into the cooling drum to accelerate cooling, 
and this likely decreased the roaster operator's exposure.

Task sampling results for grinding unflavored beans were higher than task sampling results for the roasting beans task. Compared to grinding unflavored beans, task sampling results during grinding of flavored beans were more than two times higher for diacetyl and more than three times higher for 2,3-pentanedione. The personal TWA air concentrations of 2,3-pentanedione on employees who performed the grinding flavored beans task were below the NIOSH REL. However, personal average air concentrations depend on how much time an employee spends doing each task and how much time is spent around higher exposure tasks. It should be noted that grinding was performed infrequently because the majority of sales were whole bean. Although all personal and area TWA air concentrations of diacetyl and 2,3-pentanedione for the grinding area were below the NIOSH RELs, if grinding were performed more often, TWA air concentrations for the alpha-diketones could have been elevated; this was the case at another coffee processing facility NIOSH evaluated [Bailey et al. 2015].

We also measured diacetyl and 2,3-pentanedione using instantaneous sampling, in which sample duration was less than 30 seconds. These instantaneous samples were collected to identify and describe point sources of diacetyl and 2,3-pentanedione. Notably, the highest instantaneous concentrations for diacetyl and 2,3-pentanedione were obtained while grinding French Roast beans that had been decaffeinated using the methylene chloride method. The United States Food and Drug Administration allows methylene chloride in decaffeinated roasted coffee as a residue at a level not to exceed $10 \mathrm{ppb}$ from its use as a solvent in the coffee decaffeination process [21 CFR 173.255]. We did not detect methylene chloride in the instantaneous sample taken during grinding French Roast beans that had been decaffeinated using the methylene chloride method. The high instantaneous levels of diacetyl and 2,3-pentanedione measured during grinding of these decaffeinated beans and while an employee was packaging French Roast ground coffee in small foil bags were likely a result of release of these compounds during the grinding process and because of the increased surface area of the ground coffee [Akiyama et al. 2003]. The amount of time roasted beans had been left to off-gas could also be responsible for differences in some of the instantaneous sample results. The high diacetyl and 2,3-pentanedione results obtained during a simulation of stirring overroasted French Roast beans in a storage bin might reflect that the bin had not been opened to package the beans, and the compounds had accumulated within the bin. Our finding of instantaneous concentrations of $7.6 \mathrm{ppb}$ for 2,3-pentanedione and lower than the LOD for diacetyl while pouring flavoring liquid into the flavoring bucket could indicate the flavoring manufacturer used 2,3-pentanedione as a substitute for diacetyl in the liquid flavorings. The instantaneous sampling results for dumping roasted beans from the roaster into the cooling bin were among the lowest we measured during the site visit. Overall, the instantaneous sampling results suggest that the major point sources of diacetyl and 2,3-pentanedione at this facility are the grinder while grinding coffee beans and storage bins used to hold off-gassing whole bean or ground coffee before the coffee is packaged.

The amount of time roasted beans had been left to off-gas could also be responsible for differences in headspace analysis results. The headspace results for diacetyl of the bulk sample of over-roasted French Roast that had been in a closed bin for three days was the highest of 
all bulk samples obtained. Similarly, the French Roast that was roasted and then left to offgas for one day before grinding had lower diacetyl and 2,3-pentanedione headspace results than French Roast beans that were roasted and ground on the same day. Additionally, headspace results of bulk samples of liquid flavorings were all higher, from almost two to more than 100 times as high, for 2,3-pentanedione than for diacetyl, which could indicate use of 2,3-pentanedione as a substitute for diacetyl in the liquid flavorings.

Another alpha-diketone produced naturally during the coffee roasting process and used in the food industry, although to a lesser extent than diacetyl and 2,3-pentanedione, is 2,3-hexanedione. The respiratory toxicity of 2,3-hexanedione appears to be lower than diacetyl and 2,3-pentanedione, although it is likely not free of toxicity [Morgan et al. 2016]. Across all sample types, results for 2,3-hexanedione were low. The highest levels of 2,3-hexanedione were obtained in the instantaneous samples that were also the highest in diacetyl and 2,3-pentanedione (grinding and a simulation of removing the lid from the bin and then stirring overroasted French Roast beans with a scoop). The vast majority of all other samples were below the LOD for 2,3-hexanedione.

Our continuous measurements of total VOCs, although not specific for diacetyl or 2,3-pentanedione, indicated the average total VOCs increased steadily during both mornings in the production room next to the roaster. Measurement of total VOCs includes numerous alphadiketones and many other volatile compounds. The individual levels of each compound included in a total VOC measurement can vary widely [Rhoades 1960; Akiyama 2003; Shibamoto 2015]. On both days, sharp increases in average total VOCs were recorded during the times flavoring and grinding flavored beans occurred in the adjacent warehouse, which was separated from the production room by an internal wall. Notably, there was a square opening in this internal wall (Figure 10) with an accessory fan positioned to blow air from the production room into the warehouse. 


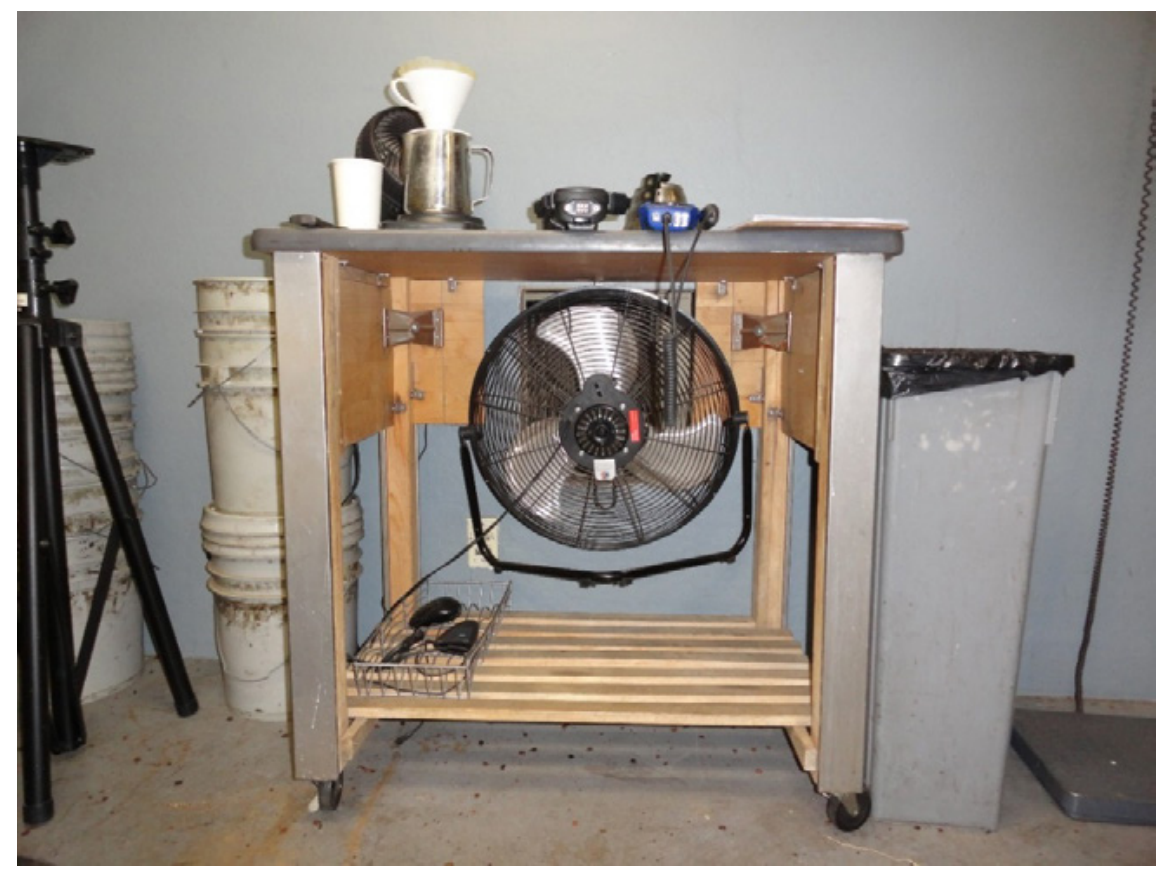

Figure 10. Square opening in wall between production room and warehouse with accessory fan that when operating blows air from production room into warehouse, NIOSH survey, February 2016

The roaster was positioned directly next to the square opening on the production side of the wall, and the grinder and flavoring station were tucked into a corner directly next to the square hole on the warehouse side of the wall. The accessory fan was typically used to exhaust hot air from the production room during roasting. During our site visit, the outside temperature was unseasonably cool, and this accessory fan was not in use. It is possible the VOCs generated during flavoring and grinding flavored beans traveled from the grinding/flavoring area in the warehouse into the production room through the square opening in the wall and were then recorded on the continuous monitoring instruments in the production room. The sharp decrease in average total VOCs on February 2, 2016 might have been caused by the roaster being turned back on, thus increasing the amount of air being exhausted to the outside via the roaster ventilation in the production room.

Continuous measurements of total VOCs were also taken during flavoring and grinding of flavored beans tasks. The highest average total VOCs were recorded near the breathing zone of an employee during grinding of flavored beans. The various peaks during this task could be explained by the grinder periodically jamming and the employee using a gloved hand to manually mix and break up the sticky flavored beans in the grinder hopper. Although other measurements taken in the breathing zone of an employee while flavoring beans and in the grinding/flavoring area while flavored beans were being ground were lower, many of the measurements taken during these tasks were above the highest measurement recorded (about $1,700 \mathrm{ppb}$ average total VOCs) across both sampling days in the production room near the roaster. The location of the grinder and flavoring station tucked into a corner of the warehouse reduced the air circulation, potentially contributing to higher VOC concentrations 
around these processes, especially when the accessory fan positioned at the square hole in the nearby wall was off. Relocation of grinding and flavoring to a dedicated workspace with increased ventilation would help reduce VOC concentrations around these tasks.

We obtained high continuous measurements of average total VOCs at the lips of open storage bins containing over-roasted French Roast (in a bin that had not been opened for over one day) and Italian Roast. Other measurements taken at the lips of open storage bins containing light roast and ground French Roast were lower, but all of the measurements of these sources were also above the highest measurement recorded across both sampling days in the production room near the roaster. We also measured high levels of $\mathrm{CO}_{2}$ (up to 2,284 ppm) and CO (up to $223.7 \mathrm{ppm}$ ) at the lips of the open storage bins. Two storage bins of roasted coffee beans (over-roasted French Roast and Italian Roast) exceeded the NIOSH ceiling limit for $\mathrm{CO}$ of $200 \mathrm{ppm}$. However, these levels were measured at the level of the lip of the open bins so they were not representative of employee exposure standing next to a closed storage bin. As a precaution, employees should not place their heads inside the bins or directly outside uncovered bins. $\mathrm{CO}$ is a gas that can displace oxygen in the blood and deprive the brain, heart, and other vital organs of oxygen. Large amounts of CO can cause a person to lose consciousness and suffocate to death [Newton 2002; Nishimura et al. 2003; Raffel and Thompson 2013]. At high concentrations, $\mathrm{CO}_{2}$ acts as an asphyxiant and can lead to increased respiratory rate, fast heart rate, heart arrhythmias, impaired consciousness, convulsions, and death [Langford et al. 2005].

While $\mathrm{CO}$ and $\mathrm{CO}_{2}$ levels were high inside the roasted bean storage bins, $\mathrm{CO}$ and $\mathrm{CO}_{2}$ were generally low throughout the other areas of the facility. The OSHA PEL for occupational exposure to CO is 50 ppm [29 CFR 1910.1000], and the NIOSH REL is 35 ppm [NIOSH 2010]. OSHA and NIOSH limits are designed for occupational exposure measurements in manufacturing and other trades that have potential sources of carbon monoxide (e.g., coffee roasting, vehicle exhaust, diesel engine exhaust, welding). Typical levels of CO in offices are 0-5 ppm [Illinois Department of Public Health 2016]. Measurements of CO in the shared office and the production area ranged from zero ppm to $3.7 \mathrm{ppm}$.

In addition to off-gassing from roast coffee, $\mathrm{CO}_{2}$ is a normal constituent of exhaled breath. Thus, $\mathrm{CO}_{2}$ will also increase during building occupancy [ANSI/ASHRAE 2016]. Generally, indoor $\mathrm{CO}_{2}$ concentrations should not be greater than $700 \mathrm{ppm}$ above outdoor $\mathrm{CO}_{2}$ concentrations. This typically corresponds to indoor concentrations below 1,200 ppm because outdoor $\mathrm{CO}_{2}$ concentrations usually range between $375 \mathrm{ppm}$ to $500 \mathrm{ppm}$. Measurements of $\mathrm{CO}_{2}$ in the shared office and the production area ranged from $398 \mathrm{ppm}$ to $1,102 \mathrm{ppm}$. If indoor $\mathrm{CO}_{2}$ concentrations become elevated, the source of the increased levels should be determined and appropriate levels of outdoor air should be brought into the ventilation system. Considering the floor space of the facility and using ANSI/ASHRAE Standard 62.1-2016, Appendix A as a guide, roughly $400 \mathrm{cfm}$ of outdoor air should be introduced to the entire facility at maximum occupancy.

One limitation of interpreting continuous measurements is the results can only be summarized within the context of tasks known to have occurred. For example, increases in VOCs, $\mathrm{CO}_{2}$, or $\mathrm{CO}$ could be explained by another task that was occurring that was not captured in 
our notes.

The current configuration of the ventilation system allows for the mixing of production room air with the office area air when operating. The square opening in the wall between the production room and the warehouse might allow VOCs from either side to enter the opposite side, depending on accessory fan operation. When the accessory fan is used to remove warm air from the production room, the air could be pulled directly into the area where flavoring and grinding take place, which could contribute to higher VOC concentrations. Conversely, the grinding and flavoring activities were performed in the corner of the warehouse directly next to the wall opening; therefore, when the accessory fan is not on and the roaster is running, the opening in the wall might allow for VOCs from the grinding and flavoring tasks to enter the production room. In addition, there was a window between the production room and the shared office that was often open and a grille-covered opening above the door between the production room and the office areas. Ideally, the production area air should not mix with the air of the office areas to prevent the migration of VOCs. The window between the production room and the shared office should be kept closed at all times to further minimize the direct entrainment of production area air into the office areas. The grille-covered opening above the production room door should also be closed off to prevent migration of air from the production room into the office areas. To improve overall air quality in the showroom, the container for drain contents from the espresso machine in the showroom should be emptied regularly.

The buildup of mineral deposits on the rooftop evaporative cooler and on the mobile unit in the warehouse can lessen the ability of the units to cool and decrease the life of the units. Following manufacturer's guidelines for routine maintenance of both the rooftop and mobile evaporative cooler units should help prevent scale and mineral deposit formation. The roaster exhaust stack on the roof should be cleaned in accordance with manufacturer instructions to prevent any possible safety hazards, improve roaster performance, and enhance energy efficiency.

The musty odors reported in the owner's office might be related to water intrusion as evidenced by the water staining on the structural beam above the ceiling tiles. Research has found that damp building conditions can lead to respiratory illnesses in occupants. Dampness in buildings can occur for a variety of reasons such as high indoor humidity, condensation, and roof leaks. Damp building conditions promote the growth of mold, bacteria, and other microbial agents, as well as dust mites and cockroaches. Dampness can also contribute to the breakdown of building materials and furniture. Musty odors are a sign of microbial contamination. Building occupants in damp buildings can be exposed to pollutants in the air from biological contaminants and the breakdown of building materials.

Comprehensive reviews have been conducted of previous scientific studies evaluating the development of health effects caused by exposures from damp indoor conditions. The findings comprise risks of developing upper and lower respiratory symptoms. Additional illnesses associated with damp indoor conditions are asthma development and exacerbation, hypersensitivity pneumonitis, respiratory infections, allergic rhinitis, bronchitis, and eczema [Mendell et al. 2011; WHO 2009]. NIOSH has published an Alert, Preventing Occupational Respira- 
tory Disease from Exposures Caused by Dampness in Office Buildings, Schools, and Other Nonindustrial Buildings that provides information on respiratory disease related to indoor dampness and recommendations for preventing and remediating damp buildings [NIOSH 2012]. A copy of the Alert can be found on the NIOSH website at http://www.cdc.gov/niosh/ docs/2013-102/.

Additionally, animals or animal products such as dander, hair, fur, saliva, and body wastes contain allergens that can cause respiratory and skin disorders. The protein in urine from rats and mice is a potent allergen. When it dries, it can become airborne [EPA 2012]. Many infectious diseases can also result from exposure to rodent feces and urine [CDC 2011]. An effective pest control program is the primary strategy for preventing human exposure to rodent diseases. This is achieved by cleanliness, eliminating food sources, sealing rodent entries into the work area, and trapping rodents in and around the workplace. For more information, the Centers for Disease Control and Prevention provides guidance on preventing rodent infestation and cleaning up after rodents at http://www.cdc.gov/rodents/. Following a written pest control program that includes procedures, recordkeeping materials, verification procedures, and frequency would aid in controlling pests and preventing exposures to pests in the workplace.

\section{Conclusions}

Full-shift personal exposures to diacetyl and 2,3-pentanedione were low at this coffee processing facility. All personal TWA air concentrations of diacetyl and 2,3-pentanedione were below the NIOSH RELs of 5 ppb and 9.3 ppb, respectively. Diacetyl and 2,3-pentanedione levels associated with roasting were low. Packaging tasks, specifically packaging ground French Roast, had the highest maximum diacetyl air concentration, likely because of the greater surface area of ground coffee for off-gassing. We observed higher levels of 2,3-pentanedione than diacetyl during flavoring of roasted beans. Higher levels of 2,3-pentanedione associated with flavorings could indicate the flavoring manufacturer used 2,3-pentanedione as a substitute for diacetyl in the liquid flavorings. We observed high instantaneous levels of diacetyl and 2,3-pentanedione during grinding, packaging of ground coffee, and at storage bins of roasted coffee, suggesting that these places could be the major point sources of diacetyl and 2,3-pentanedione at this coffee processing facility. $\mathrm{CO}$ and $\mathrm{CO}_{2}$ levels were low throughout most of the facility, and the highest $\mathrm{CO}$ and $\mathrm{CO}_{2}$ levels were observed at the openings of uncovered roasted bean storage bins.

\section{Recommendations}

On the basis of our findings, we recommend the actions listed below. Our recommendations are based on an approach known as the hierarchy of controls. This approach groups actions by their likely effectiveness in reducing or removing hazards. In most cases, the preferred approach is to eliminate hazardous materials or processes and install engineering controls to reduce exposure or shield employees. Until such controls are in place, or if they are not effective or feasible, administrative measures and personal protective equipment might be needed. 


\section{Elimination}

Elimination and substitution of a toxic/hazardous process or material have traditionally been highly effective means for reducing hazards. However, these may not be feasible approaches in this facility, given that diacetyl, 2,3-pentanedione, and 2,3-hexanedione are naturally produced and released during the coffee bean roasting and grinding processes. Substitution for diacetyl in flavorings is particularly challenging, because little is known about the health effects of substitute flavorings. Available information on the diacetyl substitute 2,3-pentanedione indicates that it has similar toxicity to diacetyl, which raises concerns that other substitutes with similar chemical structure might also be respiratory toxins. It is also important to note that some flavoring mixtures that contain diacetyl, 2,3-pentanedione, or substitutes do not list these alpha-diketones as ingredients [Day et al. 2011].

\section{Engineering Controls}

Engineering controls reduce employees' exposures by removing the hazard from the process or by placing a barrier between the hazard and the employee. Engineering controls protect employees effectively without placing primary responsibility of implementation on the employee.

1. The ventilation system was configured for re-circulation of air in the office areas and production room with no fresh air supply, and there were opportunities for air from the production room to enter the office areas. To help prevent mixing of production room air with the office area air, work with the building owner or a ventilation engineer to modify the existing ventilation system.

a. The showroom/reception, kitchen, and office areas should be separate from the production room and warehouse areas.

b. Ensure that new system configurations allow for appropriate levels of outdoor air into all areas.

2. Although we do not yet know if exposures to diacetyl and 2,3-pentanedione at the levels we measured during short-term tasks (that we could not compare to either the full-shift TWA or the 15 minute STEL) are harmful, as a precaution consider improving the ventilation around tasks that involve grinding unflavored or flavored roasted beans and packaging ground coffee. For example, consider working with a ventilation engineer to install local exhaust ventilation systems to reduce air concentrations of alpha-diketones at the sources of generation (grinding) or higher exposure (during packaging when employees interact with open storage bins containing roasted coffee).

\section{Administrative Controls}

The term administrative controls refers to employer-dictated work practices and policies to reduce or prevent hazardous exposures. Their effectiveness depends on employer commitment and employee acceptance. Regular monitoring and reinforcement are necessary to ensure that policies and procedures are followed consistently. 
1. Although we do not yet know if exposures to diacetyl and 2,3-pentanedione at the levels we measured during short-term tasks (that we could not compare to either the full-shift TWA or the 15 minute STEL), are harmful, as a precaution consider taking the following steps to reduce exposures:

a. Limit access to the area during higher exposure tasks (flavoring, grinding, packaging);

b. Relocate higher exposure tasks to a more naturally well-ventilated area, such as next to an open warehouse bay door;

c. Weather permitting, open the warehouse bay door and use accessory fans to exhaust and circulate air to reduce concentrations of alpha-diketones.

2. Continue to cover bins of roasted beans to aid in reducing the overall emission of alpha-diketones and other chemicals (e.g., $\mathrm{CO}, \mathrm{CO}_{2}$ ) into the workplace and lower employee exposure.

3. Workers should avoid placing their heads near or inside roasted bean bins to reduce exposures to VOCs, $\mathrm{CO}$, and $\mathrm{CO}_{2}$.

4. To prevent air from moving from the production areas into the office areas:

a. Keep the window between the production room and the shared office closed at all times.

b. Close the louvered vent above the door that separates the production room and the kitchen and office areas.

5. Regularly empty the espresso machine discharge container located under the cabinet in the showroom.

6. Follow manufacturer's guidelines for routine maintenance of both the rooftop and mobile evaporative cooler to keep water fresh and to prevent scale and mineral deposit formation.

7. Periodically clean the roaster's exhaust according to manufacturer instructions to remove chaff build up to reduce a fire hazard and to improve the efficiency, energy usage, and roaster performance.

8. Identify and repair the source of moisture incursion. Remove moisture-damaged materials and remediate with proper containment to minimize further exposure.

9. If not in place, develop a written pest control program that includes procedures, recordkeeping materials, verification procedures, and frequency. If a written program already exists, assess the pest control procedures and determine if updates are needed. If needed, contact pest control experts who can evaluate your plan for completeness and effectiveness. 
10. Ensure employees understand potential hazards (e.g., diacetyl, 2,3-pentanedione, CO, $\mathrm{CO}_{2}$ ) in the workplace and how to protect themselves. OSHA's Hazard Communication Standard, also known as the "Right to Know Law" [29 CFR 1910.1200] requires that employees are informed and trained on potential work hazards and associated safe practices, procedures, and protective measures.

a. Information about diacetyl and 2,3-pentanedione can be found on the Coffee Processing Facilities webpage on the NIOSH Flavoring-Related Lung Disease website at http://www.cdc.gov/niosh/topics/flavorings/processing.html.

b. Information about $\mathrm{CO}$ can be found on the Agency for Toxic Substances and Disease Registry website at http://www.atsdr.cdc.gov/toxfaqs/ TF.asp?id=1163\&tid=253

c. Information about $\mathrm{CO}_{2}$ can be found on the Department of the Interior Bureau of Land Management website at https://www.blm.gov/style/medialib/blm/wy/ information/NEPA/cfodocs/howell.Par.2800.File.dat/25apxC.pdf

11. Employees should report new, persistent, or worsening symptoms to their personal healthcare providers and, as instructed by their employer, to a designated individual at their workplace.

\section{Personal Protective Equipment}

Personal protective equipment is the least effective means for controlling hazardous exposures. Proper use of personal protective equipment requires a comprehensive program and a high level of employee and management involvement and commitment. The right personal protective equipment must be chosen for each hazard. Supporting programs such as training, change-out schedules, and medical assessment might be needed. Personal protective equipment should not be the sole method for controlling hazardous exposures. Rather, personal protective equipment should be used until effective engineering and administrative controls are in place.

Respiratory protection should be used for exposure situations when engineering controls cannot reduce exposures to concentrations below the NIOSH RELs for diacetyl and 2,3-pentanedione [NIOSH 2016]. None of the personal or area TWA air samples taken inside the facility using standard OSHA methods were above the NIOSH RELs for diacetyl or 2,3-pentanedione. We did not collect 15-minute samples at this facility with the intention to compare to the NIOSH STELs; instead, we sampled by task, with varying durations, to understand what tasks have higher exposures to diacetyl and 2,3-pentanedione. One task sample (taken during flavoring coffee) had a duration of 15 minutes, and those results did not exceed the NIOSH STELs for diacetyl or 2,3-pentanedione. One task sample (taken during packaging ground French Roast into small foil bags) exceeded the NIOSH STEL for diacetyl. However, this task had a duration of 55 minutes, so these results indicate there is a potential to exceed the STEL during any 15-minute period during that task. Therefore, we recommend reducing exposures through engineering and administrative controls. If exposures are not below the NIOSH STELs with these measures, respiratory protection would be the next step. 


\section{Medical Monitoring}

The purpose of a medical monitoring program is to help assure the health of employees who have workplace exposures to health hazards (e.g., diacetyl, 2,3-pentanedione) known to pose risk for potentially serious health conditions or illnesses.

1. Known cases of coffee processing workers diagnosed with obliterative bronchiolitis had exposure to flavored coffee or worked in areas that flavor coffee [Bailey et al. 2015]. Because this facility flavors coffee and headspace analyses of liquid flavorings used in this facility identified diacetyl, 2,3-pentanedione, and/or 2,3-hexanedione (Table A5), the NIOSH Criteria document [NIOSH 2016] recommends that the employer institute a medical monitoring program for all employees who work in or enter areas where coffee is flavored. Employees who work in or enter these areas for 40 or more hours per year should be included in the medical monitoring program.

According to the NIOSH Criteria document [NIOSH 2016], employees should have baseline evaluations before they are allowed to work in or enter areas (as described above) where they might be exposed to diacetyl, 2,3-pentanedione, or similar flavoring compounds. The spirometry we conducted in February 2016 could serve as a baseline for survey participants. Employees in the medical monitoring program should be evaluated with a questionnaire (to obtain health and work task information) and spirometry (to assess lung function) every six months due to the potentially rapid development of lung disease. If an employee is identified to have lung disease from exposure to diacetyl, 2,3-pentanedione, or a similar flavoring compound, then all employees who perform similar job tasks or have a similar or greater potential for exposure should be evaluated every three months [NIOSH 2016]. 


\section{Appendix A: Tables}

Table A1. Time-weighted average OSHA Methods 1013/1016 personal and area air sampling results by location, NIOSH survey, February 2016

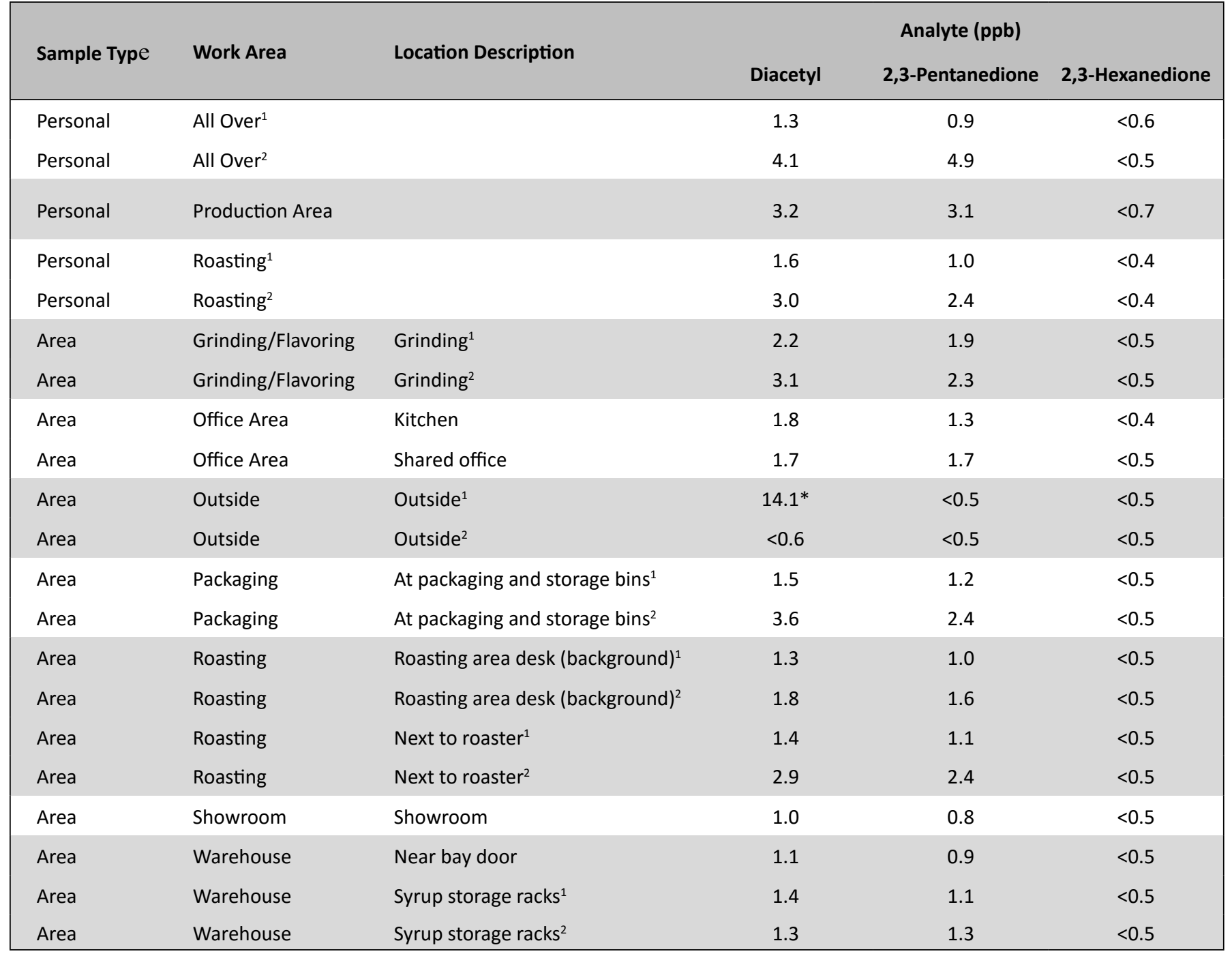

Note: OSHA: Occupational Safety and Health Administration; NIOSH: National Institute for Occupational Safety and Health; ppb: parts per billion.

$<$ indicates below the limit of detection for the instrument used to detect the analyte (i.e., diacetyl, 2,3-pentanedione, or 2,3-hexanedione)

${ }^{*}$ Above the NIOSH recommended exposure limit

${ }^{1}$ First day

${ }^{2}$ Second day 
Table A2. Time-weighted average evacuated canister method $\dagger$ area air sampling results by location, NIOSH survey, February 2016

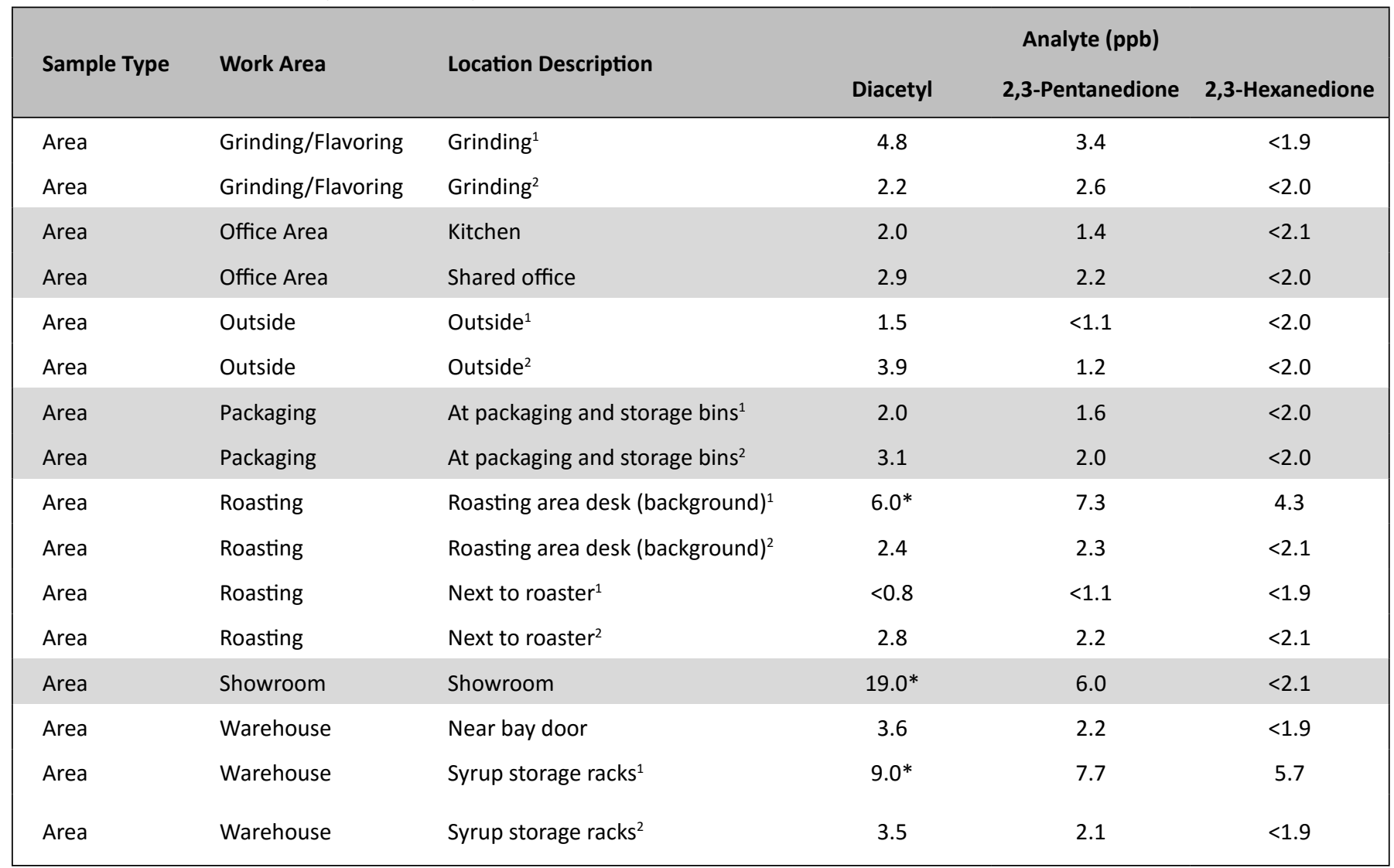

Note: NIOSH: National Institute for Occupational Safety and Health; ppb: parts per billion $<$ indicates below the limit of detection for the instrument used to detect the analyte (i.e., diacetyl, 2,3-pentanedione, or 2,3-hexanedione).

*Above NIOSH recommended exposure limit

$\dagger$ Canister method is partially validated [Lebouf et al. 2012] and will be reviewed for incorporation into the NIOSH Manual of Analytical Methods. We compare results to the NIOSH recommended exposure limit for informational purposes only.

${ }^{1}$ First day

${ }^{2}$ Second day 


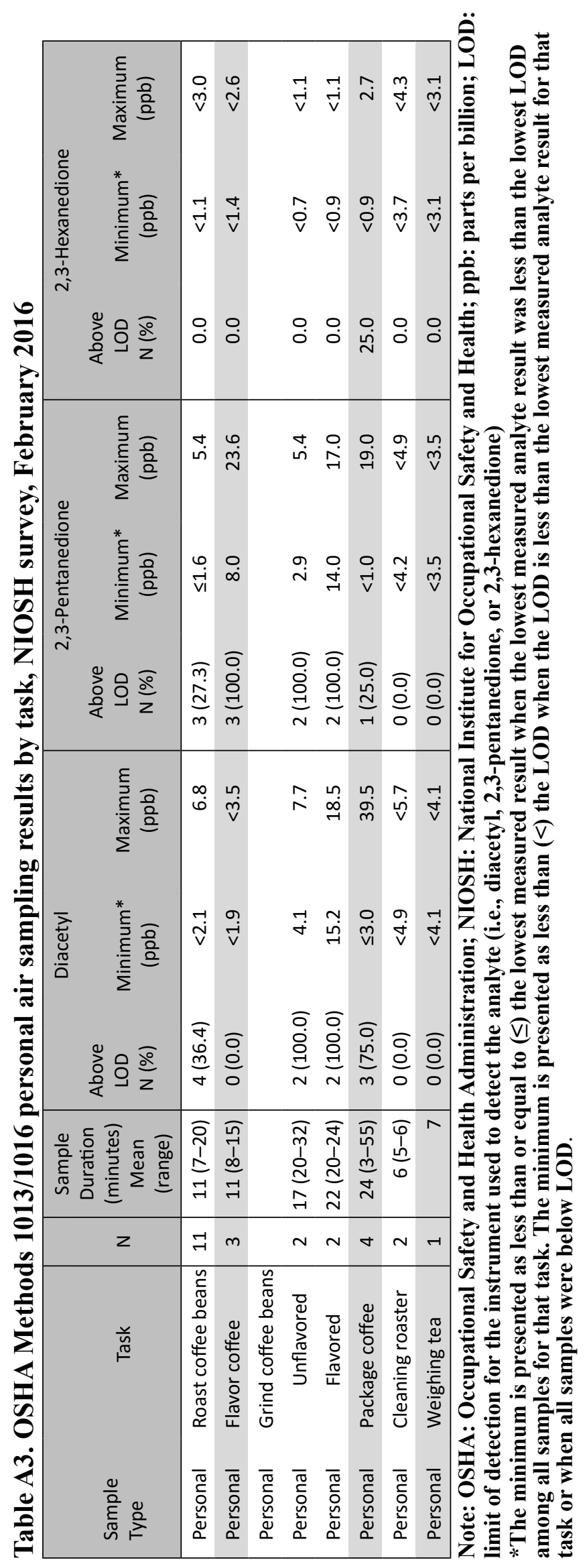




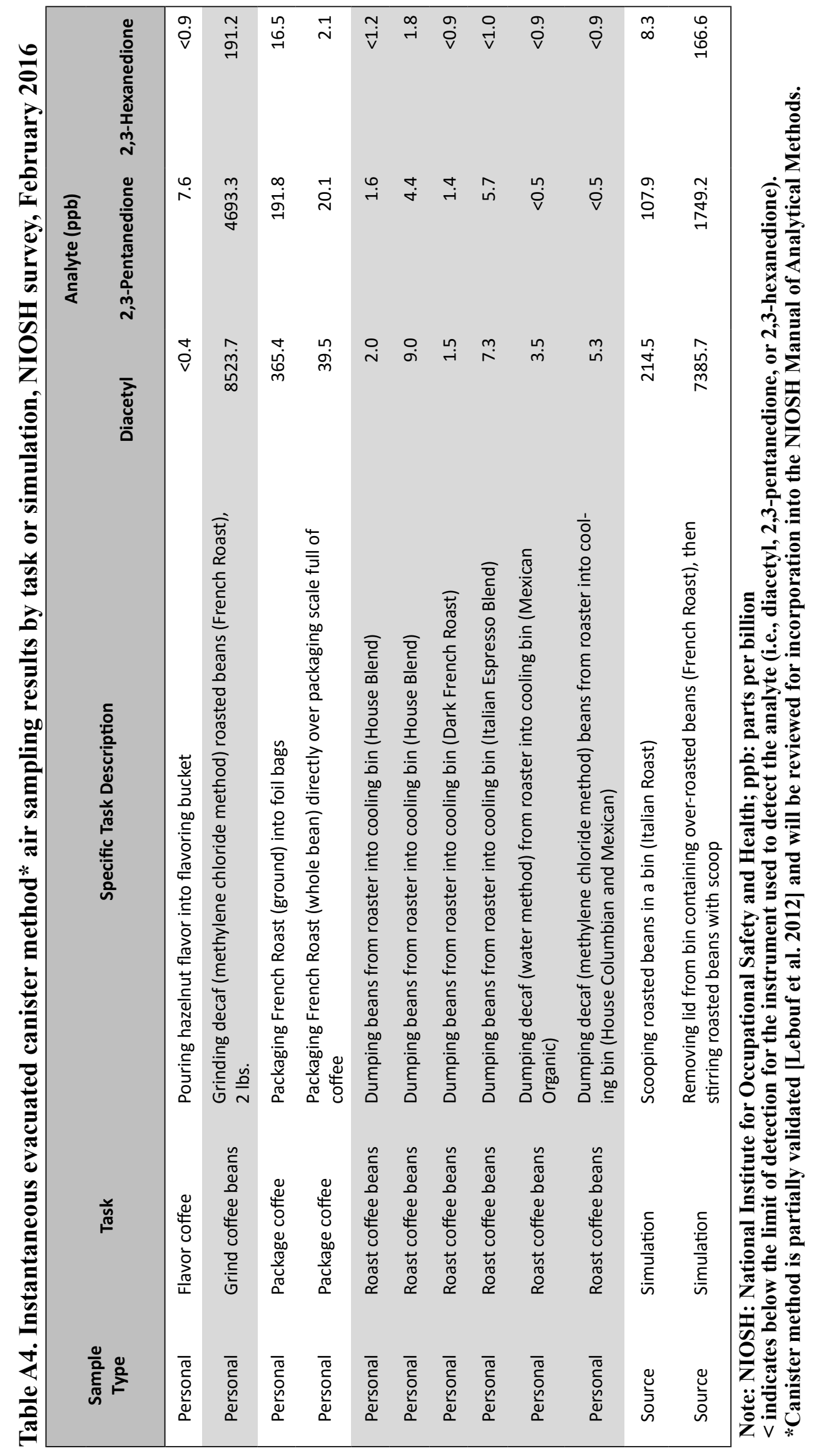


Table A5. Headspace analysis results for bulk samples of roasted coffee beans and liquid flavorings, NIOSH survey, February 2016

\begin{tabular}{|llrrr|}
\hline \multirow{2}{*}{ Sample Type } & \multicolumn{1}{c}{ Description } & \multicolumn{2}{c|}{ Analyte (ppb) } \\
& & Diacetyl & 2,3-Pentanedione & 2,3-Hexanedione \\
\hline Coffee beans & French Roast (roasted Day 1, ground Day 2) & 916 & 725 & 0 \\
Coffee beans & French Roast (roasted and ground Day 2) & 1,485 & 1,168 & 410 \\
Coffee beans & Hazelnut flavored & 628 & 611 & 220 \\
\hline Coffee beans & House Blend & 1,313 & 1,508 & 0 \\
Coffee beans & Over-roasted French Roast, in bin for 3 days & 2,409 & 892 & 0 \\
\hline Liquid flavoring & Amaretto & 264 & 491 & 521 \\
Liquid flavoring & Cinnamon nut crème & 417 & 47,848 & 0 \\
\hline Liquid flavoring & Crème brule & 369 & 29,889 & 897 \\
Liquid flavoring & French vanilla & 238 & 13,051 & 0 \\
\hline Liquid flavoring & Hazelnut & 515 & 27,264 & 0 \\
\hline Liquid flavoring & Jamaican Me Crazy ${ }^{\circledR *}$ & 676 & 2,059 & 541 \\
\hline
\end{tabular}

Note: NIOSH: National Institute for Occupational Safety and Health; ppb: parts per billion *Flavor name is a registered trademark of Flavor Dynamics, Inc. 


\section{References}

ACGIH (American Conference of Governmental Industrial Hygienist) [2016]. 2016 TLVs ${ }^{\circledR}$ and BEIs ${ }^{\circledR}$ : Threshold limit values for chemical substances and physical agents and biological exposure indices. Cincinnati, $\mathrm{OH}$ : American Conference of Governmental Industrial Hygienists.

Akiyama M, Murakami K, Ohtani N, Iwatsuki K, Sotoyama K, Wada A, Tokuno K, Iwabuchi $\mathrm{H}$, Tanaka K [2003]. Analysis of volatile compounds released during the grinding of roasted coffee beans using solid-phase microextraction. J Agric Food Chem 51(7):1961-1969.

Anderson BA, Shimoni E, Liardon R, Labuza P [2003]. The diffusion kinetics of carbon dioxide in fresh roasted and ground coffee. J Food Eng 59(1):71-78.

ANSI (American National Standards Institute)/ASHRAE [2016]. Ventilation for acceptable indoor air quality, standard 62.1-2016. Atlanta, GA: ASHRAE.

Bailey RL, Cox-Ganser JM, Duling MG, LeBouf RF, Martin SB Jr, Bledsoe TA, Green BJ, Kreiss K [2015]. Respiratory morbidity in a coffee processing workplace with sentinel obliterative bronchiolitis cases. Am J Ind Med 58(12):1235-1245.

Brashier B, Salvi S [2015]. Measuring lung function using sound waves: role of the forced oscillation technique and impulse oscillometry system. Breathe (Sheff) 11(1):57-65.

Burney P and Chinn S [1987]. Developing a new questionnaire for measuring the prevalence and distribution of asthma. Chest 91 (6 Suppl):79S-83S.

Burney PG, Laitinen LA, Perdrizet S, Huckauf H, Tattersfield AE, Chinn S, Poisson N, Heeren A, Britton JR, Jones T [1989]. Validity and repeatability of the IUATLD (1984) Bronchial symptoms questionnaire: an international comparison. Eur Respir J 2(10):940-945.

Burney PG, Luczynska C, Chinn S, Jarvis D [1994]. The European community respiratory health survey. Eur Respir J 7(5):954-960.

CDC (Centers for Disease Control and Prevention) [1996]. Third National Health and Nutrition Examination Survey, 1988-1994, NHANES III Examination Data File [CDROM] Hyattsville, Maryland: U.S. Department of Health and Human Services, Centers for Disease Control and Prevention (Public use data file documentation No. 76300).

CDC [2011]. Rodents. Available at: http://www.cdc.gov/rodents/. Date accessed: January 2017.

CDC [2013]. Obliterative bronchiolitis in workers in a coffee-processing facility-Texas, 2008-2012. Morb Mortal Wkly Rep 62(16):305-307. 
CFR (Code of Federal Regulations). Washington, DC: U.S. Government Printing Office, Office of the Federal Register.

Daglia M, Papetti A, Aceti C, Sordelli B, Spini V, Gazzani G [2007]. Isolation and determination of alpha-dicarbonyl compounds by RP-HPLC-DAD in green and roasted coffee. J Agric Food Chem 55(22):8877-8882.

Day G, LeBouf R, Grote A, Pendergrass S, Cummings K, Kreiss K, Kullman G [2011]. Identification and measurement of diacetyl substitutes in dry bakery mix production. J Occup Environ Hyg 8(2):93-103.

Duling MG, LeBouf RF, Cox-Ganser JM, Kreiss K, Martin SB Jr, Bailey RL [2016]. Environmental characterization of a coffee processing workplace with obliterative bronchiolitis in former workers. J Occup Environ Hyg 13(10):770-781.

Dweik RA, Boggs PB, Erzurum SC, Irvin CG, Leigh MW, Lundberg JO, Olin AC, Plummer AL, American Thoracic Society Committee on Interpretation of Exhaled Nitric Oxide Levels (FENO) for Clinical Applications [2011]. An official ATS clinical practice guideline: interpretation of exhaled nitric oxide levels (FENO) for clinical applications. Am J Respir Crit Care Med 184(5):602-615.

ECRHS (European Community Respiratory Health Survey) [2014]. Questionnaires, protocols and instructions. Available at: http://www.ecrhs.org/Quests.htm. Date accessed: January 2017.

EPA (Environmental Protection Agency) [2012]. Biological pollutants' impact on indoor air quality. Available at: https:/www.epa.gov/indoor-air-quality-iaq/biological-pollutantsimpact-indoor-air-quality. Date accessed: January 2017.

Ferris BG [1978]. Epidemiology standardization project. Am Rev Respir Dis 118(Suppl):1-53.

Hankinson JL, Odencrantz JR, Fedan KB [1999]. Spirometric reference values from a sample of the general U.S. population. Am J Respir Crit Care Med 159(1):179-187.

Hubbs AF, Cumpston AM, Goldsmith WT, Battelli LA, Kashon ML, Jackson MC, Frazer DG, Fedan JS, Goravanahally MP, Castranova V, Kreiss K, Willard PA, Friend S, SchweglerBerry D, Fluharty KL, Sriram K [2012]. Respiratory and olfactory cytotoxicity of inhaled 2,3-pentanedione in Sprague-Dawley rats. Am J Pathol 181(3):829-844.

Illinois Department of Public Health [2016]. Illinois department of public health guidelines for indoor air quality. Available at: http://dph.illinois.gov/topics-services/environmentalhealth-protection/toxicology/indoor-air-quality-healthy-homes/idph-guidelines-indoor-airquality. Date accessed: January 2017. 
Kanwal R, Kullman G, Piacitelli C, Boylstein R, Sahakian N, Martin S, Fedan K, Kreiss K [2006]. Evaluation of flavorings-related lung disease risk at sick microwave popcorn plants. J Occup Environ Med 48(2):149-157.

King MS, Eisenberg R, Newman JH, Tolle JJ, Harrell FE Jr, Nian H, Ninan M, Lambright ES, Sheller JR, Johnson JE, Miller RF [2011]. Constrictive bronchiolitis in soldiers returning from Iraq and Afghanistan. N Engl J Med 365(3):222-230.

Langford NJ [2005]. Carbon dioxide poisoning. Toxicol Rev 24(4):229-235.

LeBouf RF, Simmons M [2016]. Validation of evacuated canisters for sampling volatile organic compounds in healthcare settings. J Occup Environ Hyg (in press).

LeBouf RF, Stefaniak AB, Virji, MA [2012]. Validation of evacuated canisters for sampling volatile organic compounds in healthcare settings. J Environ Monit 14(3):977-983.

Mendell MJ, Mirer AG, Cheung K, Tong M, Douwes J [2011]. Respiratory and allergic health effects of dampness, mold and dampness-related agents: a review of the epidemiologic evidence. Environ Health Perspect 119(6):748-756.

Miller MR, Hankinson J, Brusasco V, Burgos F, Casaburi R, Coates A, Crapo R, Enright P, van der Grinten CP, Gustafsson P, Jensen R, Johnson DC, MacIntyre N, McKay R, Navajas D, Pedersen OF, Pellegrino R, Viegi G, Wanger J, ATS/ERS Task Force [2005]. Standardisation of spirometry. Eur Respir J 26(2):319-338.

Morgan DL, Jokinen MP, Johnson CL, Price HC, Gwinn WM, Bousquet RW, Flake GP [2016]. Chemical reactivity and respiratory toxicity of the $\alpha$-diketone flavoring agents: 2,3-butanedione, 2,3-pentanedione, and 2,3-hexanedione. Toxicol Pathol 44(5):763-783.

Morgan DL, Jokinen MP, Price HC, Gwinn WM, Palmer SM, Flake GP [2012]. Bronchial and bronchiolar fibrosis in rats exposed to 2,3-pentanedione vapors: implications for bronchiolitis obliterans in humans. Toxicol Pathol 40(3):448-465.

NCHS (National Center for Health Statistics) [2015]. National Health and Nutrition Examination Survey (NHANES). Hyattsville, Maryland: U.S. Department of Health and Human Services, Centers for Disease Control and Prevention. Available at: http://www.cdc.gov/nchs/nhanes/about_nhanes.htm. Date assessed: January 2017.

Newton J [2002]. Carbon monoxide exposure from coffee roasting. Appl Occup Environ Hyg 17(9):600-602. 
NIOSH (National Institute for Occupational Safety and Health) [2010]. NIOSH pocket guide to chemical hazards. Cincinnati, OH: U.S. Department of Health and Human Services, Centers for Disease Control and Prevention, National Institute for Occupational Safety and Health, DHHS (NIOSH) Publication No. 2010-168c.

Available at: http://www.cdc.gov/niosh/npg/. Date accessed: January 2017.

NIOSH [2012]. NIOSH Alert: Preventing occupational respiratory disease from exposures caused by dampness in office buildings, schools, and other nonindustrial buildings. DHHS (NIOSH) Publication No. 2013-102. Available at: http://www.cdc.gov/niosh/docs/2013-102/. Date accessed: January 2017.

NIOSH [2016]. Criteria for a recommended standard: occupational exposure to diacetyl and 2,3-pentanedione. U.S. Department of Health and Human Services, Centers for Disease Control and Prevention, National Institute for Occupational Safety and Health, DHHS (NIOSH) Publication No. 2016-111. Available at: https://www.cdc.gov/niosh/docs/2016-111/. Date accessed: January 2017.

Nishimura F, Abe S, Fukunaga T [2003]. Carbon monoxide poisoning from industrial coffee extraction. JAMA 290(3):334.

Oppenheimer BW, Goldring RM, Herberg ME, Hofer IS, Reyfman PA, Liautaud S, Rom WN, Reibman J, Berger KI [2007]. Distal airway function in symptomatic subjects with normal spirometry following World Trade Center dust exposure. Chest 132(4):1275-1282.

OSHA (Occupational Safety and Health Administration) [1993]. Compliance and Enforcement Activities Affected by the PELs Decision. August 5, 1993 Memorandum. Available at: https:/www.osha.gov/pls/oshaweb/owadisp.show document?p table=INTERPRETATIONS\&p id=21220. Date accessed: January 2017.

OSHA [2003]. Enforcement Policy for Respiratory Hazards Not Covered by OSHA Permissible Exposure Limits. January 24, 2003 Memorandum. Available at: https://www. osha.gov/pls/oshaweb/owadisp.show document?p_table=INTERPRETATIONS\&p $\underline{\mathrm{id}=24749}$. Date accessed: January 2017.

OSHA [2016]. Permissible exposure limits - annotated tables.

Available at: https://www.osha.gov/dsg/annotated-pels/index.html. Date accessed: January 2017.

OSHA [2008]. Sampling and analytical methods: Method 1013 - Acetoin and diacetyl. Available at: http://www.osha.gov/dts/sltc/methods/validated/1013/1013.html. Date accessed: January 2017.

OSHA [2010]. Sampling and analytical methods: Method 1016 - 2,3-pentanedione. Available at: http://www.osha.gov/dts/sltc/methods/validated/1016/1016.html. Date accessed: January 2017. 
Pellegrino R, Viegi G, Brusasco V, Crapo RO, Burgos F, Casaburi R, Coates A, van der Grinten CP, Gustafsson P, Hankinson J, Jensen R, Johnson DC, MacIntyre N, McKay R, Miller MR, Navajas D, Pedersen OF, Wanger J [2005]. Interpretative strategies for lung function tests. Eur Respir J 26(5):948-968.

Raffel JB, Thompson J [2013]. Carbon monoxide from domestic coffee roasting: a case report. Ann Intern Med 159(11):795-796.

Rhoades, JW [1960]. Analysis of the volatile constituents of coffee. J Agric Food Chem 8(2):136-141.

Shibamoto T [2015]. Volatile chemicals from thermal degradation of less volatile coffee components. In: Preedy VR, ed. Coffee in health and disease prevention. New York: Elsevier, pp. 129-135.

Smith HJ, Reinhold P, Goldman MD [2005]. Forced oscillation technique and impulse oscillometry. In: Gosselink R, Stam H, eds. European Respiratory Monograph 31: Lung Function Testing. Vol. 10. Wakefield, UK: European Respiratory Society Journals, pp. 72105.

WHO (World Health Organization) [2009]. WHO guidelines for indoor air quality: dampness and mould. Available at: http://www.who.int/indoorair/publications/7989289041683/en/. Date accessed: January 2017. 
This page left intentionally blank 
Keywords: NAICS 311920 (Coffee roasting), Arizona, diacetyl, 2,3-pentanedione, 2,3-hexanedione, coffee, flavorings, volatile organic compounds (VOCs), carbon monoxide, carbon dioxide, and indoor environmental quality. 
The Health Hazard Evaluation Program investigates possible health hazards in the workplace under the authority of the Occupational Safety and Health Act of 1970 (29 U.S.C. § 669(a) (6)). The Health Hazard Evaluation Program also provides, upon request, technical assistance to federal, state, and local agencies to investigate occupational health hazards and to prevent occupational disease or injury. Regulations guiding the Program can be found in Title 42, Code of Federal Regulations, Part 85; Requests for Health Hazard Evaluations (42 CPR Part 85).

\section{Disclaimer}

The recommendations in this report are made on the basis of the findings at the workplace evaluated and may not be applicable to other workplaces.

Mention of any company or product in this report does not constitute endorsement by the National Institute for Occupational Safety and Health (NIOSH).

Citations to Web sites external to NIOSH do not constitute NIOSH endorsement of the sponsoring organizations or their programs or products. NIOSH is not responsible for the content of these Web sites. All Web addresses referenced in this document were accessible as of the publication date.

\section{Acknowledgments}

Desktop Publisher: Tia McClelland

NIOSH Laboratory Assistance: Dru Burns, Kyle Hatcher, Ryan LeBouf, Anand Ranpara NIOSH Site Visit Team Members: Michael Beaty, Randy Boylstein, Ethan Fechter-Leggett, Marcia Stanton, Kristin Yeoman

\section{Availability of Report}

Copies of this report have been sent to the employer and employees. The state and local health department and the Occupational Safety and Health Administration Regional Office have also received a copy. This report is not copyrighted and may be freely reproduced.

This report is available at http://www.cdc.gov/niosh/hhe/reports/pdfs/2015-0147-3266.pdf.

All other HHE Reports may be found at http://www2a.cdc.gov/hhe/search.asp.

\section{Recommended citation for this report:}

NIOSH [2017]. Health hazard evaluation report: evaluation of exposures and respiratory health at a coffee processing facility. By Fechter-Leggett ED, Boylstein RJ, Stanton ML. Morgantown, WV: U.S. Department of Health and Human Services, Centers for Disease Control and Prevention, National Institute for Occupational Safety and Health, NIOSH HHE Report No. 2015-0147-3266. 
Delivering on the Nation's promise:

Safety and health at work for all people through research and prevention

To receive documents or other information about occupational safety and health topics, contact NIOSH

Telephone: 1-800-CDC-INFO (1-800-232-4636)

TTY: 1-888-232-6348

email: cdcinfo@cdc.gov

or visit the NIOSH website at http://www.cdc.gov/niosh

SAFER • HEALTHIER $\cdot$ PEOPLE $^{\text {TM }}$ 